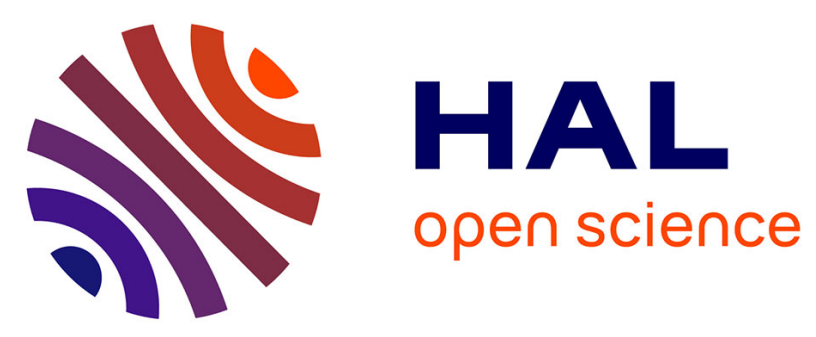

\title{
What bilateral damage of the superior parietal lobes tells us about visual attention disorders in developmental dyslexia
}

\author{
S. Valdois, D. Lassus-Sangosse, M. Lallier, O. Moreaud, L. Pisella
}

\section{To cite this version:}

S. Valdois, D. Lassus-Sangosse, M. Lallier, O. Moreaud, L. Pisella. What bilateral damage of the superior parietal lobes tells us about visual attention disorders in developmental dyslexia. Neuropsychologia, 2018, 10.1016/j.neuropsychologia.2018.08.001 . hal-02150810

\section{HAL Id: hal-02150810 \\ https://hal.science/hal-02150810}

Submitted on 25 Oct 2021

HAL is a multi-disciplinary open access archive for the deposit and dissemination of scientific research documents, whether they are published or not. The documents may come from teaching and research institutions in France or abroad, or from public or private research centers.
L'archive ouverte pluridisciplinaire HAL, est destinée au dépôt et à la diffusion de documents scientifiques de niveau recherche, publiés ou non, émanant des établissements d'enseignement et de recherche français ou étrangers, des laboratoires publics ou privés.

\section{(c) (1) $\$$}

Distributed under a Creative Commons Attribution - NonCommerciall 4.0 International 


\title{
What bilateral damage of the superior parietal lobes tells us about visual attention disorders in developmental dyslexia
}

\author{
S. Valdois ${ }^{1,2}$, D. Lassus-Sangosse ${ }^{3}$, M. Lallier $^{4}$, O. Moreaud ${ }^{1,3}$ et L. Pisella ${ }^{5}$
}

1. CNRS, LPNC UMR 5105, 38040 Grenoble, France

2. Université Grenoble Alpes, LPNC, 38040, Grenoble, France

3. CMRR, Pôle Psychiatrie, Neurologie, Rééducation neurologique, CHU GrenobleAlpes, France

4. Basque Center on Cognition, Brain and Language, 20009, San Sebastián, Spain

5. 1 ImpAct - Lyon Neuroscience Research Center, Inserm U1028, CNRS UMR 5292, Bron, France,

\begin{abstract}
:
Neuroimaging studies have identified the superior parietal lobules bilaterally as the neural substrates of reduced visual attention (VA) span in developmental dyslexia. It remains however unclear whether the VA span deficit and the deficits in temporal and spatial attention shifting also reported in dyslexic children reflect a unitary spatio-temporal deficit of attention - probably linked to general posterior parietal dysfunction- or the dysfunction of distinct attentional systems that relate to different neural substrates. We explored this issue by testing an adult patient, IG, with a specific damage of the bilateral superior parietal lobules after stroke, on tasks asessing the VA span as well as temporal and spatial attention shifting. IG demonstrated a very severe VA span deficit, but preserved temporal attention shifting. Exogenous spatial orientation shifting was spared but her performance was impaired in endogenous attention. The overall findings show that distinct sub-systems of visual attention can be dissociated within the parietal lobe, suggesting that different attentional systems associated with speficic neural networks can be selectively impaired in developmental dyslexia.
\end{abstract}

Highlights: 3 to 5 on a separate file ( 85 characters max with blanks)

Investigation of a patient with bilateral superior parietal lobe (SPL) damage

Evidence for poor visual attention span but normal temporal attention shifting

Normal exogenous but impaired endogenous spatial attention

Involvement of the SPLs in specific visual attention subskills

Different visual attention systems are involved in developmental dyslexia

Keywords: 6 Visual attention, brain damage, superior parietal lobule, developmental dyslexia, visual attention span, endogenous and exogenous spatial attention.

Fundings: This research did not receive any specific grant from funding agencies in the public, commercial or not-for-profit sectors.

\section{Introduction}


A variety of visual attention deficits has been reported in dyslexic individuals, supporting the visual attention account of developmental dyslexia (DD) (Vidyasagar \& Pammer, 2010). More specifically, three main types of deficits have been reported: a visual attention (VA) span deficit (Bosse et al., 2007), a temporal attention shifting deficit (Hari \& Renvall, 2001) and a spatial attention orienting deficit (Facoetti et al., 2010). The Visual attention (VA) span deficit results in poor multi-element parallel processing due to a reduction of the visual attention resources available for processing. Deficits in exogenous and endogenous orienting of spatial attention are also reported, together with temporal attention shifting deficits that prevent the normal processing of rapidely presented stimulus sequences. These deficits follow from difficulties to engage or disengage attention during spatial processing or fast temporal processing. Although the existence of visual attention deficits in DD is now well established, some authors propose that they reflect the dysfunction of one single attentional system (Facoetti et al., 2006; Vidyasagar \& Pammer, 2010) while others argue for two independent and functionally distinct, VA span and sluggish attentional shifting, systems that could be selectively impaired in DD (Lallier et al., 2010, 2012). Here, we will shed light on this debate from a neurobiological perspective. We reasoned that if attentional shifting and VA span deficits reflect the dysfunction of a single attention system, both skills should be implemented in the same neural network. Alternatively, two functionnally distinct attentional systems should be implemented in two anatomically distinct neural networks.

There is no doubt that the parietal cortex plays a key role in attentional processing (Friedrich et al. 1998; Corbetta and Shulman 2002, 2011) and the sluggish attentional shifting skills of dyslexic individuals have been proposed to be underpinned by a dysfunction of this brain structure (Hari and Renvall, 2001). However, attentional shifting involves several different fronto-parietal sub-networks (Chica et al., 2013; Fan \& Posner, 2002) that might be selectively affected in developmental dyslexia. From another line of research, bilateral superior parietal lobules have been identified as the cerebral correlates of the VA span, thus pointing to a dysfunction of a specific parietal area in relation to VA span deficits in DD (Lobier et al., 2012, 2014; Peyrin et al., 2011, 2012; Reilhac, 2013). Since the role of the SPLs in VA span performance is now well established, the aim of the current study was to determine whether the SPLs are further involved in the other visual attention disorders reported in developmental dyslexia. In order to do so, we will study the performance of a brain-damaged patient to determine whether (i) a bilateral SPL damage impacts both VA span and temporal/spatial attention shifting performance or (ii) a SPLs damage selectively impairs performance on VA span tasks without impacting temporal/spatial attention shifting. Evidence for (i) would support the unitary account of the visual attention deficit in developmental dyslexia, while evidence for (ii) would suggest that two distinct attentional systems independently contribute to reading acquisition and developmental dyslexia.

\subsection{A VA span deficit in developmental dyslexia}

Dyslexic individuals who show a VA span deficit (Bosse et al., 2007; Dubois et al., 2010; Germano et al., 2014; Zoubrinetzky et al., 2014, 2016) can only process a reduced number of distinct visual elements simultaneously due to limited visual attention capacity (Bogon et al., 2014 ; Lobier et al., 2013). Behaviourally, the deficit is highlighted using tasks of letter 
report in which a multi-consonant string is briefly and centrally presented on a computer screen and subjects are required to orally report either all the consonant names (global report) or the name of a single cued consonant (partial report). Some dyslexic children exhibit impaired performance on these tasks despite preserved fast single letter identification. However, the deficit is not specific to letter-strings since similar poor performance is observed when using digits instead of letters within strings (Valdois et al., 2012). Importantly, children with poor performance in global and partial letter reports are similarly impaired in categorization tasks that do not require oral report and do not involve verbal material (Lobier et al., 2012a). Thus, these individuals show difficulties at multielement parallel processing, regardless of the type of stimuli to be processed. In addition, Lassus-Sangosse et al. (2008) showed that the VA span deficit is specific to parallel processing: the dyslexic participants who were impaired at processing the 5-consonant strings in parallel could report as many letters as the controls when the five consonants were displayed sequentially, one at a time, at the center of the computer screen (see also Valdois et al., 2011). There is also evidence that the deficit is not specific to horizontal displays but extends to circular presentations (Dubois et al., 2010), which could explain why poor VA span also affects performance in non-linear visual search tasks (Lallier et al., 2013) and why VA span is higher in individuals who play action video games than in non-players (Antzaka et al., 2017). Overall, the available behavioural data points towards a visuallydriven deficit that reflects a limitation in the amount of attentional resources available for multiple visual-element parallel processing.

Neuroimaging studies report the hypoactivation of the bilateral SPLs in dyslexic individuals with a VA span deficit (Peyrin et al. 2011, 2012; Reilhac et al. 2013). Indeed, the SPLs were found activated under conditions of multi-element processing in normal readers (Lobier et al., 2012) and selectively underactivated in VA span-impaired dyslexic individuals (Lobier et al., 2014). Importantly, similar hypoactivation of the SPLs was found regardless of the alphanumeric or nonalphanumeric nature of the stimuli. These findings suggest that the SPLs are specifically involved in the simultaneous processing of multiple visual elements. Importantly, the link between VA span and the SPLs is specific. In the study of two contrasted cases, Peyrin et al. (2012) showed that underactivation of the SPLs during multielement processing was only found in the dyslexic participant with a VA span deficit whereas the same brain regions were normally activated in the participant with a selective phonological deficit. This link is further supported by training studies, showing that the intensive use of a training program targetting VA span skills resulted in increased activation of the SPLs (Valdois et al., 2014). In sum, it is now well established that the SPLs are the cerebral correlates of the VA span.

\subsection{A temporal attention shifting deficit in developmental dyslexia}

Temporal attention shifting deficits have been reported in developmental dyslexia in tasks that require the rapid (10 stimuli per second) sequential processing of stimuli, such as stream segregation and attentional blink tasks (Hari \& Renvall, 2001). Deficits on these tasks are interpreted as reflecting sluggish attentional shifting, a difficulty to automatically disengage the focus of attention from one stimulus to reengage it onto another stimulus appearing briefly after (Hari \& Renvall, 2001). 
In visual stream segregation tasks, two visual stimuli alternate between two different locations. When the two stimuli are temporaly far apart, they are perceived as one stream, suggesting that attention covertly shifted from one location to the other. However, when the time interval between the two visual stimuli is shortened, they are perceived as two alternating flashing stimuli at distinct positions --two distinct streams-because the attentional focus can no longer shift fast enough. The stream segregation threshold corresponds to the time interval at which perception switches from one to two streams and indicates the fastest visual attentional shifting speed. Dyslexic children were reported to have higher visual stream segregation thresholds than normal readers, suggesting a reduced speed of automatic attentional shifting (Lallier et al., 2010a; see also Lallier et al. 2009 for evidence on adult participants).

Results from studies using the attentional blink paradigm yielded similar conclusions. In the attentional blink paradigm, the visual stimuli presented in rapid succession are all displayed at the same spatial location. The participants are engaged in a dual task procedure which requires identifying a first target and then detecting a second target that is displayed at different time lags from the first target's presentation time. The probability to detect the second target decreases for the shortest lags -- participants are transiently blind to the target-- and progressively improves for longer lags. While normal readers fail to detect a second target that is presented within the first $500 \mathrm{~ms}$ after the first target, the attentional blink is abnormally prolonged in dyslexic individuals (Buchholz \& Davies, 2007; Hari et al., 1999; Lallier et al., 2010b; Visser et al., 2004).

The parietal cortex has been proposed to be the neural substrate of the attentional blink deficit (Hari \& Renvall, 2001; Hommel, Kessler, Schmitz, Gross, Akyürek, Shapiro \& Schnitzler, 2006). In healthy individuals, Marois et al. (2000) identified the right parietal sulcus as the neural correlates of the attention system involved in the attentional blink paradigm, which is consistent with data from transcranial magnetic stimulation (Cooper, Humphreys, Hulleman, Praamstra \& Georgeson, 2004). Shapiro et al. (2002) showed that the attentional blink more frequently followed from lesions of the temporo-parietal junction than of the SPLs in brain-damaged patients. The overall findings suggest that a right parietal sulcus dysfunction might account for visual sluggish attentional shifting skills in dyslexic individuals.

\subsection{A spatial attention shifting deficit in developmental dyslexia}

Developmental dyslexia has also been associated with deficits in visuo-spatial attention. A deficit in orienting spatial attention was hightlighted using the spatial cueing paradigm, a task originally designed by Posner (1980). In this paradigm, a target to be detected is preceded by a briefly presented cue that orient attention towards the target location (valid condition) or the opposite side (invalid condition). Valid cues trigger faster reaction times due to enhanced processing at the attended location. Invalid cues require to reallocate attention towards the target location, thus yielding slower reaction times. In exogenous cueing conditions, the cue is displayed in the periphery at the target location while it is centrally displayed in the endogneous condition and is predictive of the target location which appears in the periphery. Exogenous cueing involves automatic stimulus-driven attention 
shifting towards the target location while endogenous cueing requires top-down voluntary attention.

Both adults and children with developmental dyslexia show orienting difficulties on spatial cueing tasks (Brannan \& Williams, 1987; Facoetti et al., 2006). Reduced sensitivity to exogenous cues was repeatedly reported in dyslexic individuals (Brannan \& Williams, 1987; Facoetti et al., 2000, 2005, 2010a; Roach \& Hogben, 2004) and spatial attention inefficient automatic orienting characterizes preliterate children with familial risk for developmental dyslexia (Facoetti et al., 2010b). Endogenous cueing was less systematically explored in developmental dyslexia and yielded more discrepant results. In some studies, a reduced cueing effect was reported in both the exogenous and the endogenous spatial cueing paradigms (Facoetti et al., 2006) but other studies reported normal cueing effect in the endogenous condition (Facoetti et al., 2000). In the studies where stimulus onset asynchrony (SOA) was manipulated, a reduced cueing effect was reported at short $100 \mathrm{~ms}$ SOA but an amplified cueing effect at long $350 \mathrm{~ms}$ SOA in the exogenous condition (Ruffino et al., 2014). In many studies, the spatial cueing deficit was found to only characterize a subset of dyslexic children who were severely impaired in pseudo-word reading accuracy (Facoetti et al., 2006, 2010a; Ruffino et al., 2010).

Physiological studies of spatial attention orienting in healthy individuals have demonstrated the involvement of a bilateral network with core regions in parietal and frontal areas (Nobre et al., 1997; Wojciulik \& Kanwisher, 1999; Yantis et al., 2002). Endogenous attention has been postulated to be implemented in a dorsal fronto-parietal network which includes the SPL bilaterally (Corbetta \& Schulman, 2002; Shomstein \& Behrmann, 2010; Chica et al., 2013). Exogenous attention would rely on a ventral fronto-parietal network, including the right temporo-parietal junction as a core region (Corbetta at al., 2000; Corbetta \& Schulman, 2002; Shomstein \& Behrmann, 2010). However, the anatomical segregation of the two exogenous and endogenous attention systems is still debated (Chica et al., 2013). One cause of this ongoing debate is that the lesion of the ventral fronto-parietal network affects the dorsal one (Corbetta \& Shulman, 2011); Conversely, a lesion of the SPL does not seem to affect the ventral fronto-parietal network (Gillebert et al. 2011; Shomstein \& Behrmann, 2010).Thus, the exploration of the exogenous and endogenous attention systems in a patient with bilateral SPL lesion is particularly relevant to distinguish the specific attentional processes in which the SPL is critically involved.

\subsection{Purpose of the current study}

The purpose of the current study is to contribute to the ongoing debate on attentional deficits in developmental dyslexia. Decades of behavioural research have provided evidence for the presence of VA span, temporal and spatial attention shifting deficits but their co-occurrence or independence in the dyslexic population remains an unresolved issue. Only a few studies have explored temporal and spatial attention in the same dyslexic participants. Ruffino et al. (2014) administered an exogenous spatial attention task and an original temporal attention task to groups of dyslexic children. Only the subset of dyslexic participants with the most severe pseudo-word reading accuracy deficit demonstrated impaired performance in visual attention. Temporal and spatial attention deficits were found to co-occur, suggesting that spatial exogenous and temporal attention may depend on the same functional system implemented by the same neural network. With respect to spatial 
attention, current studies did not provide strong evidence for the independence or association of exogenous and endogenous attention deficits in developmental dyslexia. Some suggest deficits of the two spatial attention systems in developmental dyslexia (Facoetti et al., 2006) while others suggest a selective deficit of exogenous (stimulus-diven) attention (Facoetti et al., 2010b). Besides, evidence for a dissociation between VA span deficit and attention shifting deficits in developmental dyslexia is also scarce. Lallier et al. (2010c) administered tasks of attentional blink to a phonologically-impaired dyslexic participant and reported evidence for impaired temporal attention shifting despite preserved VA span abilities. Strong behavioural evidence is thus lacking in support or against the independence of the various visual attention disorders reported in developmental dyslexia.

At the neurobiological level, the spatial and temporal attention deficit in developmental dyslexia, as well as the VA span deficit are attributed to a parietal dysfunction (Hari \& Renvall, 2001; Gori \& Facoetti, 2014 ; Peyrin et al., 2011, 2012 ; Vidyasagar \& Pammer, 2010). In addition, there is strong evidence that the SPLs bilaterally are the neural substrates of the VA span deficit but the question remains whether these structures are also part of the neural substrates of temporal and spatial attention deficits in developmental dyslexia.

To address this issue, we will explore VA span, temporal attention and endogenous/exogenous spatial attention skills in a brain-damaged patient who suffered a bilateral SPL stroke. Based on previous evidence, this patient is expected to demonstrate a severe VA span deficit. Additional deficits on temporal and spatial attention tasks would be found if all these attentional components are implemented in the same parietal regions. Alternatively, a dissociation between poor VA span but preserved temporal and spatial attention in our patient would demonstrate that several attentional systems may independently contribute to developmental dyslexia. In addition, the performance of our patient should be impaired in condition of endogenous cueing if primarily dependent on the dorsal fronto-parietal network including the SPLs but preserved in exogenous cueing if implemented by the temporo-parietal junction of the ventral network (Chica et al., 2013; Shomstein et al. 2010).

\section{Case report}

IG is a right-handed 44 year-old woman who suffered from an ischemic stroke when she was 29. The lesion involved the whole area 7 and the intraparietal sulcus in both hemispheres, as well as the upper part of Brodmann's areas 19, 18 and 39 (corresponding to area PEG as defined by Eidelberg and Galaburda 1984) but spared area 40 and the tempo-parietal junction (see Figure 1a). Visual fields showed a partial right inferior homonymous quadrantanopia with temporal crescent sparing (Figure 1b), due to the subcortical damage of the optical radiations below the parietal cortex in the left hemisphere. Her visual acuity was normal (7/10 and 8/10 for the right and left eye respectively). She initially demonstrated a simultanagnosia and an impairment of online automatic visuo-motor guidance (i.e., bilateral optic ataxia) but never showed any hemineglect syndrome.

The present experiment was conducted 15 years after IG's ischemic stroke long after clinical simultanagnosia had regressed. IG was administered a general neuropsychological screening battery to explore the cognitive long-term effects of her brain damage. Table 1 
summarizes her performance on tests of intellectual efficiency, executive and attentional functions, language and visual abilities.

As shown on Table 1, IG's verbal IQ was well within the normal range $(I Q=110)$. She shows preserved executive functions (Wisconsin Card Sorting Test (WCST); Godefroy \& Grefex, 2008), good verbal short-term memory (WAIS IV forward and backward digit span) and good oral language abilities (Verbal IQ: Similitudes, Vocabulary, Informations; picture naming from the Becs Greco, Merck et al. (2011); Pseudo-word Repetition, alphabetic and semantic fluency). Her reading was functional and she did not complain for reading difficulties. However, she exhibited a reading age of 9 years 1 month on the Alouette Reading Test (Lefavrais, 1967), suggesting limited reading skills. Note that IG reported no history of reading or learning problems in childhood but she left school at the age of 16 (after having completed a professional certificate of dressmaker). Her limited reading abilities may thus primarily reflect her socio-educational level but we cannot exclude some additional effect due to her ischemic accident.

Figure 1: A-Horizontal section through IG's brain, visualised with structural MRI. B- Visual field perimetry for patient IG showing quadrantanopia in the right lower quadrant of the visual field of both eyes.

\section{A-}

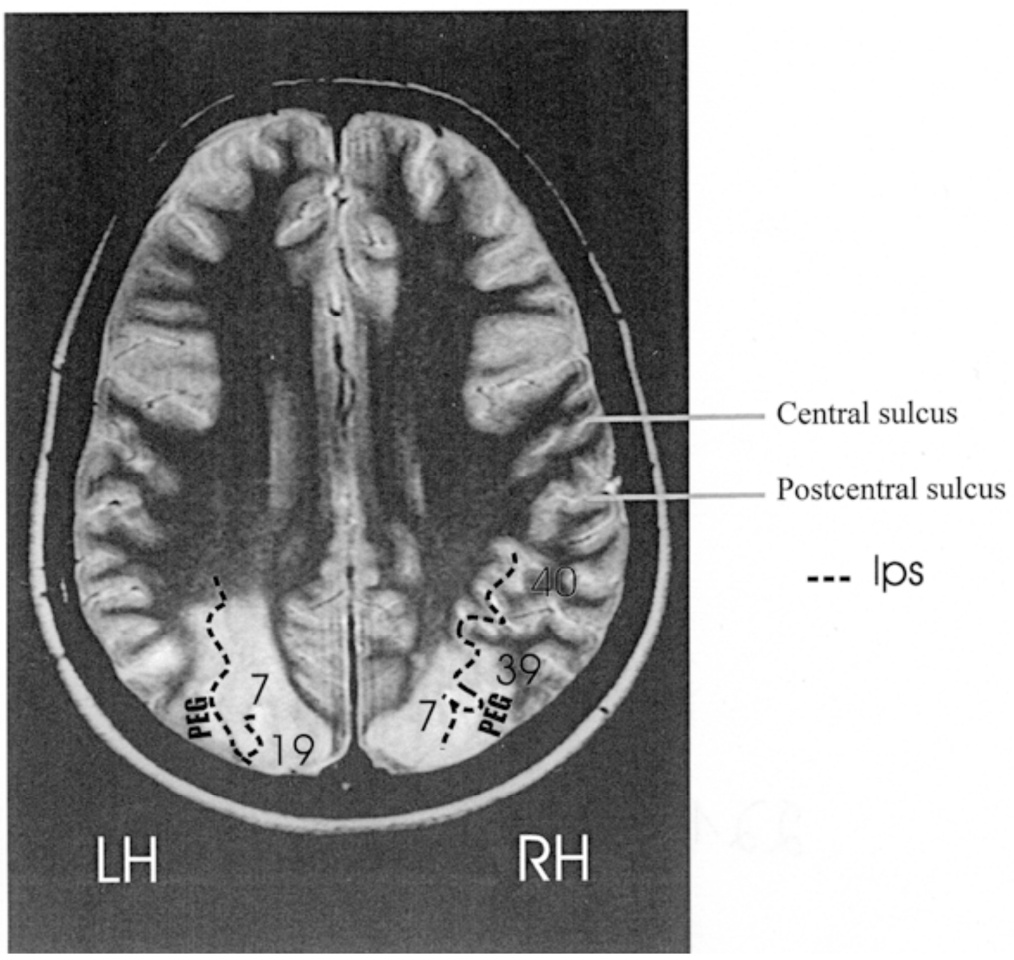

$B$ 
Left Eye

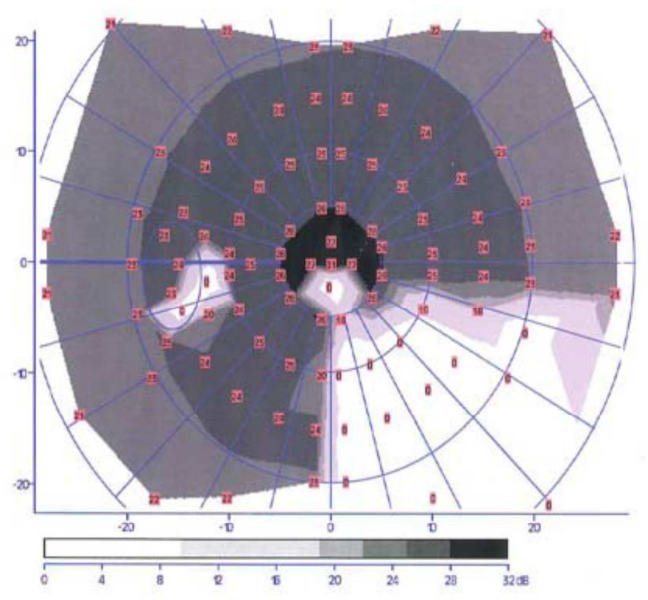

1
Right Eye

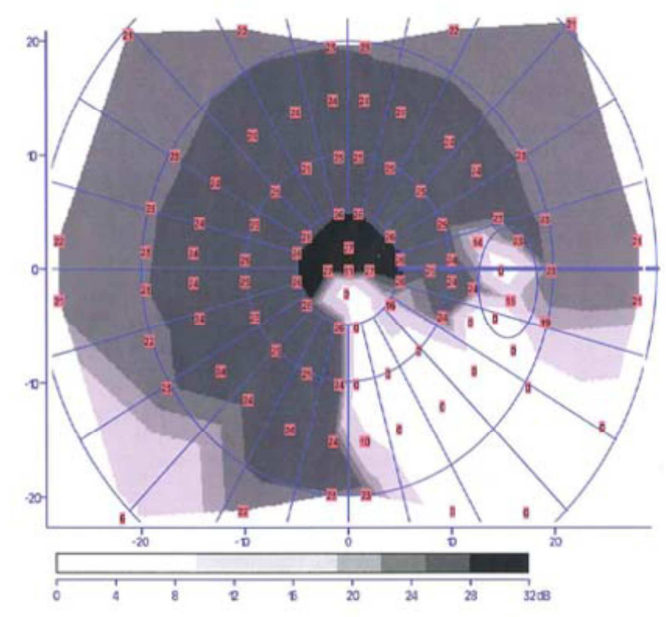


2 Table 1: IG general neuropsychological assessment $\left({ }^{* *}=p<.05\right)$

\begin{tabular}{|c|c|c|c|}
\hline TASKS & IG & $\begin{array}{c}\text { Mean (SD) } \\
\text { controls }\end{array}$ & $\begin{array}{l}\text { t modified, Z-score or } \\
\text { standard score } \\
(\mathrm{SS}) / \text { percentile } \\
\end{array}$ \\
\hline $\begin{array}{l}\text { Intellectual efficiency } \\
\text { Verbal IQ (WAIS IV) }\end{array}$ & 110 & $100(15)$ & $z=0.66 \sigma$ \\
\hline $\begin{array}{l}\text { Executive functions } \\
\text { Wisconsin Category } \\
\text { Wisconsin Errors }\end{array}$ & $\begin{array}{l}6 \\
8\end{array}$ & $\begin{array}{l}5.95(0.22) \\
3.73(2.66)\end{array}$ & $\begin{array}{l}t=0.22 \\
t=-1.59\end{array}$ \\
\hline $\begin{array}{l}\text { Verbal Short term memory } \\
\text { Forward digit span } \\
\text { Backward digit span }\end{array}$ & $\begin{array}{l}7 \\
5\end{array}$ & $\begin{array}{l}6.2(1.3) \\
4.8(1.4)\end{array}$ & $\begin{array}{l}t=0.61 ; \text { ou } S S=11 / 19 \\
t=0.14 \text { ou } S S=11 / 19\end{array}$ \\
\hline $\begin{array}{l}\text { Oral Language } \\
\text { Picture naming } \\
\text { Pseudo-word repetition } \\
\text { Semantic fluency } \\
\text { Alphabetic fluency }\end{array}$ & $\begin{array}{c}40 / 40 \\
88 / 92 \\
53 \\
25\end{array}$ & $\begin{array}{c}39.5(0.7) \\
86.47(2.62) \\
39.83(7.78) \\
28.86(5.55)\end{array}$ & $\begin{array}{l}t=0.68 \\
t=0.58 \\
t=1.68 \\
t=-0.69\end{array}$ \\
\hline $\begin{array}{l}\text { Written Language } \\
\text { Reading Age }\end{array}$ & 9yrs 1mth & & \\
\hline $\begin{array}{c}\text { Auditory attention } \\
\text { PASAT }\end{array}$ & 58 & & $75^{\circ} \mathrm{Ct}$ \\
\hline \begin{tabular}{c} 
Visual attention \\
TMT A \\
TMT B \\
Bells Test \\
\multicolumn{1}{c}{ score } \\
Time sec \\
Line bisection \\
Long lines \\
Short lines
\end{tabular} & $\begin{array}{c}105 \\
208 \\
\\
34 / 35 \\
222 \\
\\
+0.875 \mathrm{~cm} \\
-0.05 \mathrm{~cm}\end{array}$ & $\begin{array}{l}42(14) \\
66(24)\end{array}$ & $\begin{array}{c}t=-4.47^{* *} \\
t=-5.88^{* *} \\
(30-50)^{\circ} \mathrm{ct} \\
<5^{\circ} \mathrm{C} t^{* *} \\
(50-60)^{\circ} \mathrm{ct} \\
(40-50)^{\circ} \mathrm{ct}\end{array}$ \\
\hline $\begin{array}{l}\text { Visual processing (VOSP) } \\
\text { Incomplete letters } \\
\text { Dot counting } \\
\text { Position discrimination }\end{array}$ & $\begin{array}{c}17 / 20 \\
4 / 10 \\
15 / 20\end{array}$ & $\begin{array}{l}\text { Cut off : } 17 \\
\text { Cut off : } 8 \\
\text { Cut off : } 18\end{array}$ & $\begin{array}{c}\quad=\text { cut off } \\
z=-9.68 \sigma^{* *} \\
<\text { cut off }\end{array}$ \\
\hline $\begin{array}{l}\text { Single Letter identification } \\
\text { threshold }\end{array}$ & 33 & $33.3(2.25)$ & $z=-0.13 \sigma$ \\
\hline
\end{tabular}

Assessment of her attention abilities revealed good auditory but poor visual attention skills. She performed well within the normal range on the Paced Auditory Serial Addition Test (PASAT, Gronwall \& Sampson, 1974; French adaptation: Mazza \& Naegele, 2004), which suggests normal auditory attention and good calculation skills. In contrast, her poor performance on the two conditions of the Trail Making Test (TMT; Godefroy \& Grefex, 2008) and on the Bells Test (Gauthier, Dehaut \& Joanette, 1986) suggests poor visual attention processing abilities. Her performance on the latter task was characterized by good accuracy, showing preserved abilities to identify a specific target among visually similar distractors but at the cost of very long search time. In the same way, her very slow performance in condition A of the Trail Making Test --that requires connecting numbers in sequential order -- may primarily reflect a difficulty to locate the target numbers. Although performance on the TMT and Bells Test suggests impaired visual attention, IG's normal performance on the line bisection task (Schenkenberg et al. 1980) shows that her visual attention disorder is rather specific. IG's shows no sign of visual neglect either investigated through the line bisection task or through the very sensitive Bells Test. Actually, she never exhibited any hemineglect syndrome, even when her visual attention abilities were first explored just after her stroke when she was 29 (Pisella et al. 2000). The absence of hemineglect is well in line with her 
very focal brain damage that spared the occipito-temporo-parietal junction. IG seems more specifically impaired when the task requires the processing of multiple elements as in the Bells test and TMT (but not in the line bisection task), a processing ability also involved in the dot counting and position discrimination subtests of the VOSP (Visual Object and Space Perception, Warrington \& James, 1991) and in the incomplete letter subtest (Boucard \& Humphreys, 1992). In contrast, her performance in single letter visual processing is remarkably preserved. In this task, single letters were randomly presented at the center of the screen for a short duration (varying from $33 \mathrm{~ms}$ to $101 \mathrm{~ms}$ ), immediately followed by a mask. IG was able to identify $90 \%$ single letters presented for only $33 \mathrm{~ms}$ (and all the letters displayed for longer durations) a performance well within the norm of adult skilled readers (Valdois, Guinet \& Embs, 2017).

\section{Experimental investigation}

IG was administered tasks of VA span, temporal and spatial attention shifting. The classical paradigms of global and partial report that require parallel processing of briefly presented 5consonant strings were used to assess her VA span abilities (Experiment 1) together with an additional task of global report in which string-length and inter-letter spacing were varied (Experiment 2) to determine whether the deficit extended to shorter strings and reflected potential crowding effects. A sequential multi-letter processing task was further administered to ensure that the deficit highlighted in the VA span tasks was specific to simultaneous processing (Experiment 3). Temporal attention was assessed through visual tasks of stream segregation (Experiment 4) and attentional blink (Experiment 5) while exogenous (Experiment 6) and endogenous (Experiment 7) spatial cueing paradigms were used to assess IG's spatial attention skills.

In each experiment, IG's performance was compared to that of a control participant, ERB, and to control groups. ERB is a 46 year-old woman who reported no academic difficuly and was matched in age and school level with IG. She was right-handed and reported no medical or psychiatric illness. She exhibited a reading age of 14 years 3 months well within the normal range of young adults, suggesting that IG reading age $(R A=9 ; 1)$ may have been affected by her brain damage. ERB was administered all the experimental tasks that were proposed to IG. Groups of RA-matched control participants or healthy young adults were further used for comparison. In particular, IG performance was compared to the performance of a group of reading age-matched (RA) controls in Experiment 1 and 2 to ensure that her poor performance on the tasks was not just the consequence of her poor reading level. The RA-matched control participants were administered the Alouette Reading Test to ensure that their reading level, as a group, was comparable to that of IG (all ps $>0.05$ ). The control participants attended school regularly and had never repeated a grade. None of them exhibited a reading disorder. Specific information on the control groups is provided at the beginning of each experiment.

In each experiment, modified t-tests were used to compare IG performance with ERB performance by referencing the difference to the control sample (Crawford, Garthwaite \& Wood, 2010). This method allowed testing whether the difference between ERB and IG performance was greater than the difference observed among pairs of controls, in which case they were said to differ significantly. In each task, IG performance was further compared to the control group performance using modified t-tests, as recommended when 
the size of the normative sample is small (Crawford et al., 2002). Moreover, this method is only minimally sensitive to departure from normal distribution (Crawford \& Garthwaite, 2006), which was required here as a lot of measured abilities were within the competence of most non-dyslexic control participants.

\subsection{Visual attention span assessment}

\subsubsection{Experiment 1: Global and Partial Report}

Participants: IG, ERB and a RA-matched control group of 108 5th Grade children (Mean $C A=127.10 ; S D=4.07$ ) matched for reading age (Mean $R A=120.89 ; S D=20.06 ; p>.05$ ) with IG participated in Experiment 1.

Stimuli: Random five letter-strings (e.g., RHSDM) were built up from 10 consonants (B, $P, T$, $F, L, M, D, S, R, H)$. The letters were presented in upper case (Geneva, 24) in black on a white background. The 5-consonant strings never matched the skeleton of a real word (e.g., FLMBR for FLAMBER "burn"). The strings included no repeated letter, no frequent bigram (as $\mathrm{BR}$ or $\mathrm{PL}$ ) and no meaningful substring (e.g., no frequent abbreviations as HLM in French). To control for potential crowding effects, the space between adjacent letters was increased $(0.6 \mathrm{~cm})$. The whole line subtended an angle of $5.4^{\circ}$. Twenty five-letter strings were successively presented in global report. Each letter was used ten times, twice in each position. Fifty random five-letter strings were displayed in partial report. Each letter occurred 25 times and appeared five times in each position.

Procedure: At the beginning of each trial, a central fixation point was presented for $1000 \mathrm{~ms}$ followed by a blank screen for $50 \mathrm{~ms}$. Then, a letter-string was displayed at the center of the screen for $200 \mathrm{~ms}$, a duration long enough for an extended glimpse, yet too short for a useful eye movement (Figure 2a). In global report, a white screen was presented at the offset of the letter string and children had to report verbally as many letters as possible immediately after the disappearance of the string. In partial report, a vertical bar indicating the position of the letter to be reported was presented for $50 \mathrm{~ms}\left(1.1^{\circ}\right.$ below the target letter) at the offset of the letter-string (Figure 2b). Each letter was used as target once in each position. Participants were asked to report the cued letter only. In the two global and partial report tasks, the experimental trials were preceded of 10 training trials for which participants received feedback. No feedback was given during the experimental trials. The dependent measure was the mean number of letters accurately reported (identity not location) across the 20 trials (maximal score $=100$ ) or the 50 trials for the global and partial report respectively. The partial report task was adapted to account for IG's right quadrantanopia that interfered with the presentation of the vertical cue when presented below the target in the right visual field. The vertical bar was thus presented above instead of below the target letter in both the left and right visual fields. 
A

4

5

6

7

8

9

10

11

12

(a) Global

Report

(b) Partial

Report

Global report

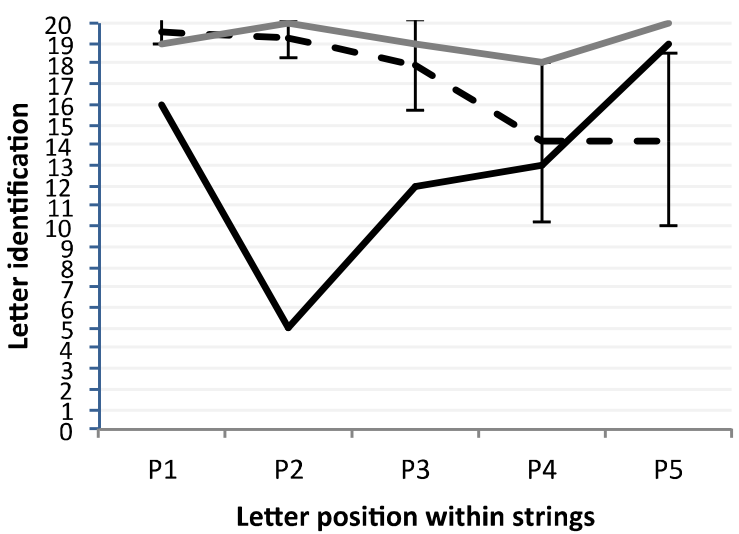

Partial report

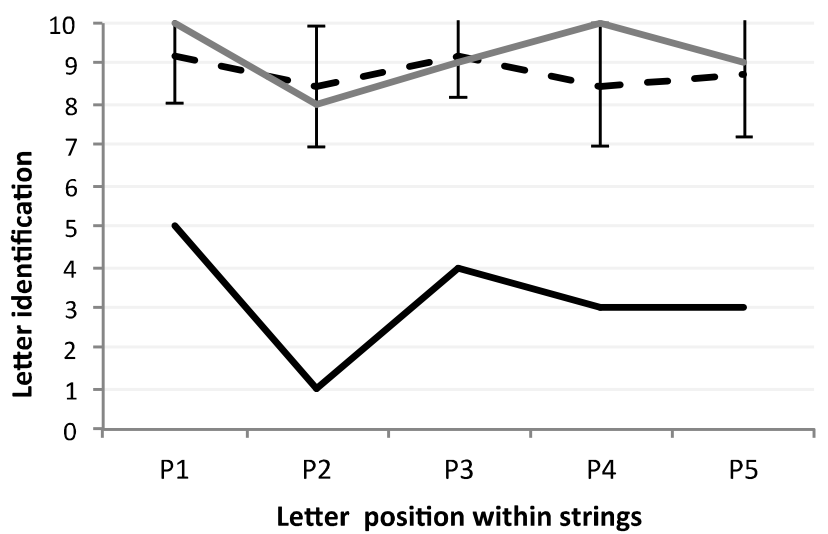

Figure 2: (A) Procedure of global (a) and partial (b) report (Experiment 1); (B) Number or 21 letters accurately identified in global and partial report as a function of letter position within strings for IG (black solid), ERB (grey solid) and the RA-matched control group (black hatch). For the controls, standard error bars are depicted for each position. 
Results:

In global report (Figure $2 B)$, IG reported 65 letters, which is significantly less $\left(\mathrm{t}_{\text {modified }}(107)=-\right.$ 2.24; $p=0.014$ ) than ERB (96 letters) and the RA-matched controls (mean RA score $=85.11$ $\left.(9.8) ; t_{\text {modified(108) }}=-2.04, p<0.05\right)$. The ANOVA computed on the control data with letter position as an intra-subject factor showed a significant letter position effect $(F(4 ; 428)=156,33 ; p<.001)$, reflecting better performance on the leftmost than the rightmost letters. Most of the variance $(90.25 \%)$ in controls was explained by a linear function. A cubic function accounted for a small additional part of variance (6.77\%). IG's response pattern did not show the left-right gradient characteristic of the controls. She was poor at identifying the letters in position 1,2 and $3\left(t_{\operatorname{modified}(108)}: \mathrm{P} 1=-5.2 ; \mathrm{P} 2=-14.8 ; \mathrm{P} 3=-2.66\right.$; all $\left.\mathrm{ps}<0.05\right)$ but showed preserved performance on the rightmost letters (P4 and P5). Her performance pattern was deviant and well described by a cubic function that accounted for $97 \%$ of variance.

In Partial Report (Figure 2B), IG only reported 16 target letters (out of 50), a performance

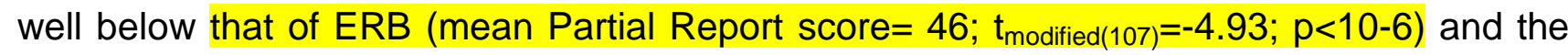
controls (mean $\left.=44,01(4.3) ; \mathrm{t}_{\text {modified(108) }}=-6.48, \mathrm{p}<0.05\right)$. Letter report was significantly impaired in IG whatever the position of the target in the string (all ts $s_{\text {modified }}<-1.66$ ). In the controls, the response pattern was characterized by a main position effect $(F(4,404)=5,66$; $\mathrm{p}<.0002)$. Regression analyses showed that $68 \%$ of the variance of RA controls' pattern was accounted for by a linear function and an additional $31.33 \%$ by a quartic function. IG's performance pattern was very atypical and could not be accounted for by either a linear or a quartic function.

\subsubsection{Experiment 2: Effect of String Length and Interletter Spacing in Global Report}

Participants: The participants were IG, ERB and the same RA-matched control group as in Experiment 1.

Stimuli: Nineteen letter-strings made of 3, 4 or 5 letters were build up from 15 consonants $(B, C, D, F, H, J, L, M, N, P, R, S, T, V)$. Each letter was around $7 \mathrm{~mm}$ in height and $5.5 \mathrm{~mm}$ in width. A given letter was never used twice in the same string and each letter was used 24 times: 10 times in the 30 5-letter strings, 8 times in the 30 4-letter strings and 6 times in the 30 5-letter strings. Each letter was used twice in each position for each of the three lengths. The 30 strings of each length were presented in two conditions of normal and large interletter spacing (Figure 3A). In the normally spaced condition, the inter-letter spacing was of 5 $\mathrm{mms}$ (close to 1 character space) whatever string length, so that strings of 3, 4 and 5 letters subtended an angle of 3 degrees, 4.2 degrees and 5.4 degrees respectively (at a distance of $50 \mathrm{~cm}$ from the computer screen). In the large spacing condition, the whole letter-string subtended an angle of $10.23^{\circ}$ (corresponding to $89.5 \mathrm{~mm}$ at a distance of $50 \mathrm{~cm}$ ) whatever the string length so that the distance between adjacent letters varied from $36.5 \mathrm{~mm}$ (around 6 character spaces) for the 3-letter strings, to $22.5 \mathrm{~mm}$ (around 4 character spaces) and 
1

$15.5 \mathrm{~mm}$ (between 2 and 3 character spaces) for the 4 and 5 -letter strings respectively. Letters were presented in upper case (Genova 24) in black on a white background.

Procedure: Each trial began with a 1000 ms fixation point, displayed at the center of the computer screen (Figure 3). This was followed by a blank screen for $50 \mathrm{~ms}$, then the letterstring was centrally displayed for $200 \mathrm{~ms}$. The six conditions of length and spacing were presented by blocks. After each trial, the participant was asked to orally report the name of the letters he had identified. In each block, the participants carried out 10 training trials with feedback. No feedback was provided during the experimental trials. The dependent measure was the number of letters accurately identified (identity not location) out of a maximal score of 75,60 and 45 for the three length-by-spacing conditions.
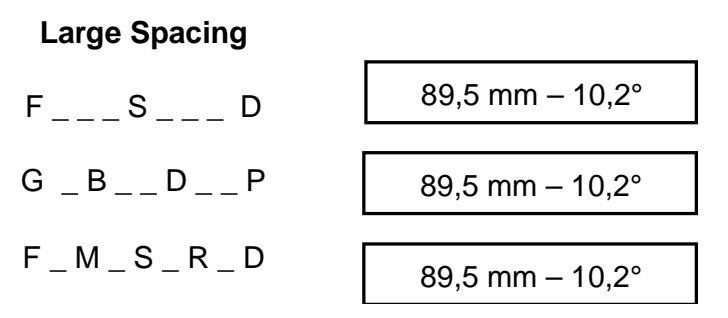
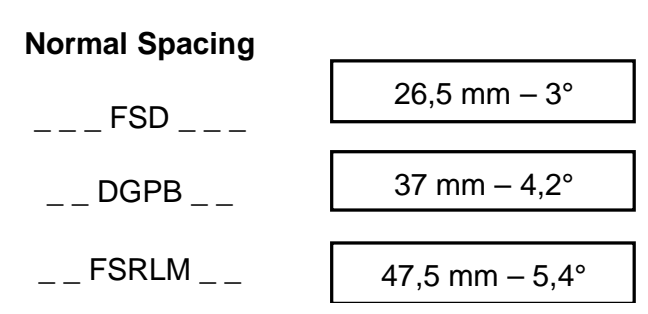

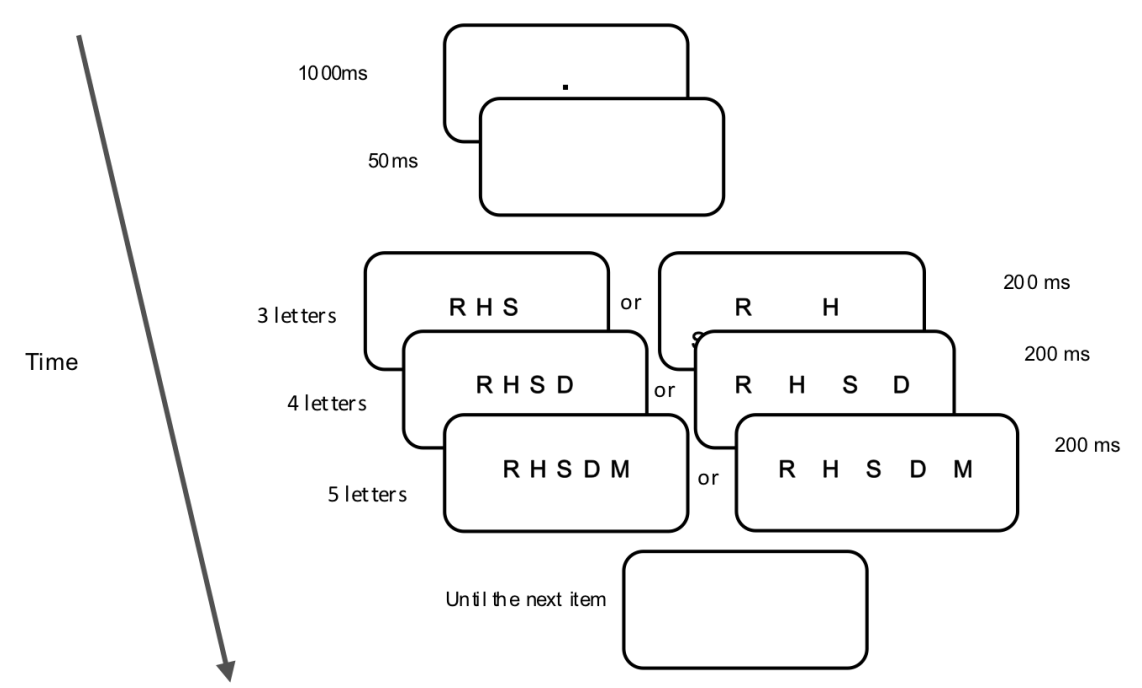

Figure 3: The spacing and length conditions of global report in Experiment 2

\section{Results}

An ANOVA with Length (3, 4 and 5 letters) and Spacing (normal and large) as within-subject factors was carried out on the accurracy rate of the RA-matched controls. Results (see Figure 4) showed a significant main effect of length $(F(2,214)=407.77 ; p<.001)$ and spacing $(F(1,107)=40.63, p<.001)$. The Length by Spacing interaction was significant $(F(2$, $214)=13,04, p<.001)$. Planned comparisons showed that a spacing effect was only found for 5-letter strings, the only condition in which more letters were accurately reported in the normal than in the large spacing condition $(81.05 \%$ vs. $77.48 \%)$. Performance of the controls on the shorter strings ( 3 and 4 letters) was not affected by spacing. As shown on 
Figure 4, IG performed lower than ERB in all conditions of length and spacing (all ts $<-1.84$,

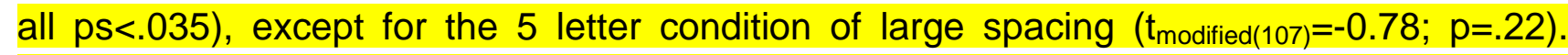
Comparison with the RA-matched group of control participants showed that IG was severely impaired. Her performance was poorer than for the controls in all conditions of length and spacing (all ts<-2.1; $p<.02)$, except again for the 5 letter condition of large spacing $\left(\mathrm{t}_{(108)}=\right.$ 1.478; $p=0.07$. IG did not show any disadvantage in the normal spacing condition as compared to the large spacing condition (normal spacing=74.74 vs. large spacing=70.81), thus showing the absence of crowding effect.

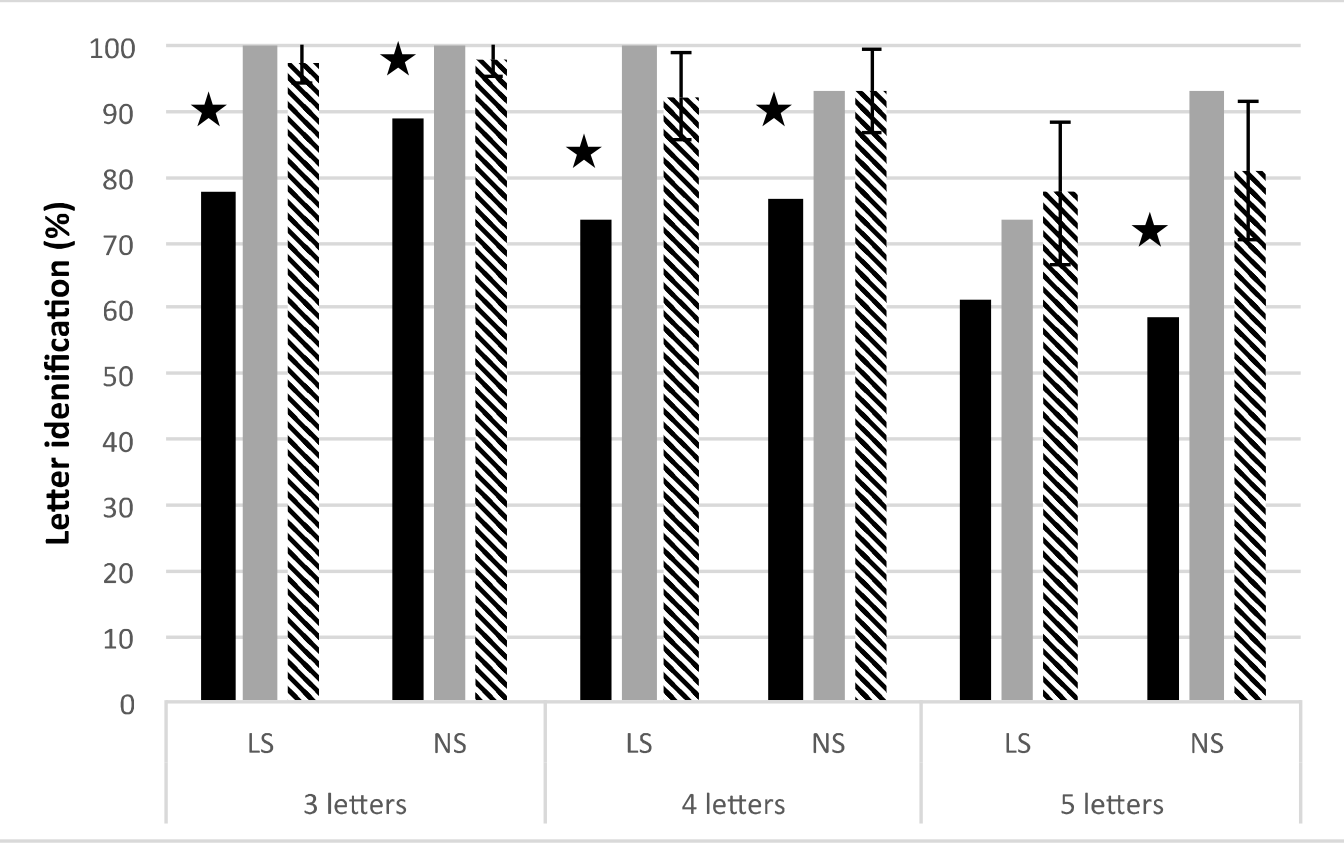

Figure 4 : Number of letters accurately identified by IG (black), ERB (grey) and the controls (hatch) in the two conditions of normal (NS) and large (LS) spacing for the 3-, 4- and 5-letter strings. The standard error bars are provided for the control group.

\subsubsection{Experiment 3: Multi-letter Sequential Report}

Participants: IG, ERB and a control group of $1024^{\text {th }}$ and $5^{\text {th }}$ grade children were recruited as controls. The control children had a mean chronological age of 11 years 4 months (mean $C A=136.33$ mths ; $S D=8.6$ ) and a similar reading age as $I G$ (mean $R A=120.02, S D=14.57$; $\mathrm{p}>$.05)

Stimuli: The strings of 5 consonants were constructed following the same constraints as in Experiment 1.

Procedure: A central fixation point was presented for $1000 \mathrm{~ms}$ followed by a blank screen for $50 \mathrm{~ms}$ (see Figure $5 \mathrm{~A}$ ). Then 5 letters were successively displayed one at a time at the center of the computer screen. Each letter was displayed for $200 \mathrm{~ms}$ and was immediately followed by the next letter $(I S I=0)$. Participants were asked to report as many letters as possible, without any order or time constraints. They started naming letters at the end of the sequential display. Ten training trials were proposed at the beginning of the task, for which participants received feedback. No feedback was given during the 20 experimental trials. The dependent measure was the number of letters accurately reported (identity not location) across the 20 trials (maximal score $=100$ ). 
A.

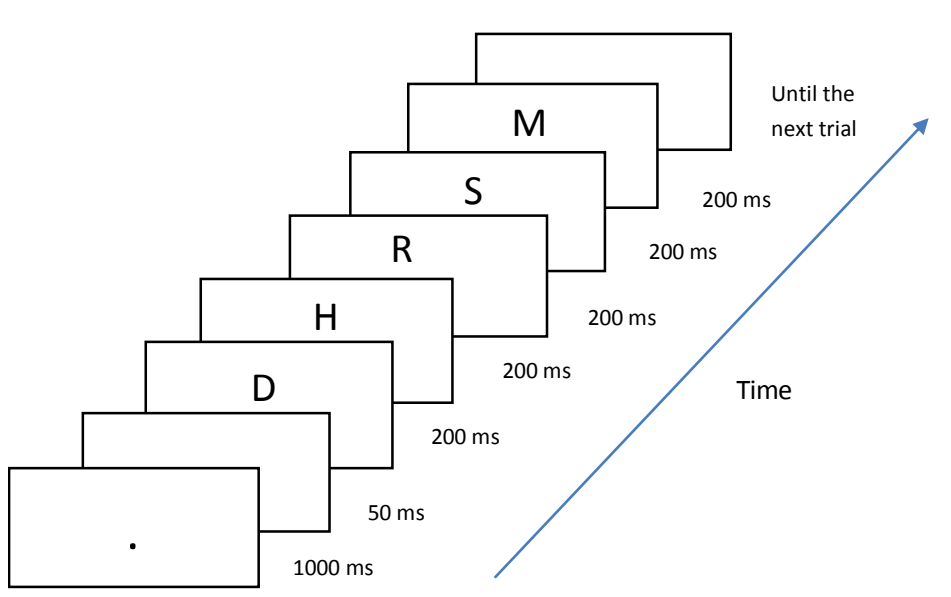

B.

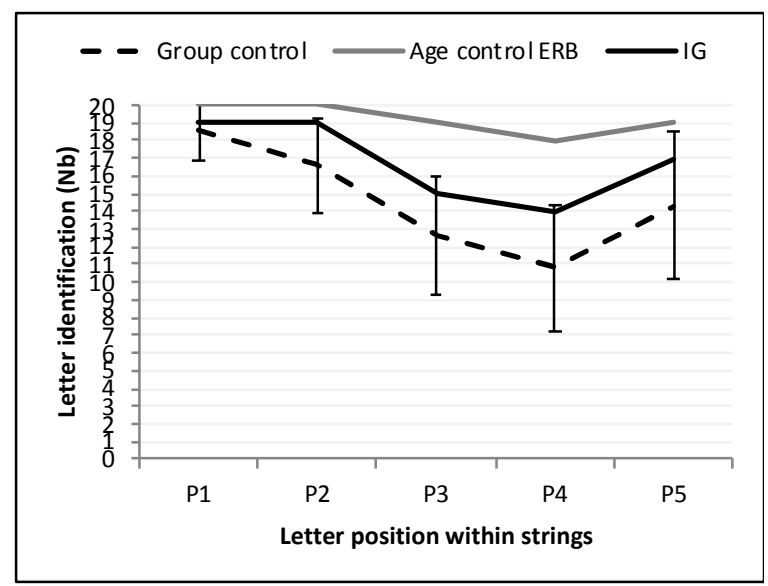

Results: The response patterns of IG, ERB and the controls in the sequential report task are illustrated on Figure $5 \mathrm{~B}$. In the control group, performance was characterized by a main position effect $(F(4,404)=128,05, p<.001)$, showing better report of the first than the last letters. IG reported as many letters as the controls in this sequential report task (84 vs. 72.95, $\mathrm{SD}=10.32$, $\left.\mathrm{t}_{\text {modified }}=1.07 ; \mathrm{p}=0.21\right)$ and as many letters as ERB $\left(\mathrm{t}_{\operatorname{modified}(102)}=-0.82\right.$; $p=0.21$ ). IG scores were within the normal range for all positions ( $t s_{\text {modified }}>0.22$; all $p>0.05$ ) and her response pattern was characterized by a cubic function as for the controls.

Figure 5: (A) The multi-letter sequential report procedure in Experiment 3; (B) Number of letters accurately reported by IG (black line), ERB (grey line) and the controls (dotted line) as a function of letter position within the sequential string. For the controls, standard error bars are depicted for each position.

\subsection{Temporal attention shifting}

\subsubsection{Experiment 4: Stream Segregation Threshold}

Participants: IG, ERB and a control group of 19 healthy young adults (mean $\mathrm{CA}=19.4$ years ; $S D=0.6$ ) who participated in Lallier et al. (2010; Experiment 2).

Stimuli: Two black dots subtending $0.1^{\circ} \times 0.1^{\circ}$ of visual angle were displayed in alternance $2^{\circ}$ above and below a fixation cross along the vertical median line of the screen (see Figure 6A). The participants were asked to fixate the central cross so that the dots were foveally presented, and could be perceived accurately without eye mouvements.

Procedure: The procedure was the same as in Lallier et al. (2010, Experiment 2). Within each trial, a fixation cross, subtending $0.5^{\circ} \times 0.5^{\circ}$ of visual angle appeared at the center of the screen for $500 \mathrm{~ms}$, followed by the two dots that alternated at different time intervals (SOAs). After each trial, the participants reported whether they had perceived one stream or two streams in a forced-choice paradigm. Each trial began with a $300 \mathrm{~ms}$ SOA, yielding a systematic one-stream answer in all participants. The SOA was then decreased by steps of $40 \mathrm{~ms}$, until the stimuli were perceived as two streams. The SOA was then increased or decreased by steps of $20 \mathrm{~ms}$ until the next perception change. Steps of $10 \mathrm{~ms}$ and $5 \mathrm{~ms}$ were then used to better estimate the segregation threshold that was defined as the mean 
SOA over the last ten trials. Before the testing phase, a short training session was proposed to the participants. During this practice period, an unambiguous one-stream stimulus $(\mathrm{SOA}=400 \mathrm{~ms})$ and an unambiguous two-stream stimulus $(\mathrm{SOA}=50 \mathrm{~ms})$ were presented to be associated with the appropriate schematic drawings (see figure 6A). After each trial, participants answered by pointing at the drawing corresponding to the pattern they had perceived. When unsure, they were instructed to guess.

A-

One stream

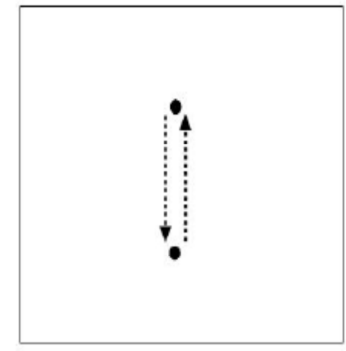

two streams

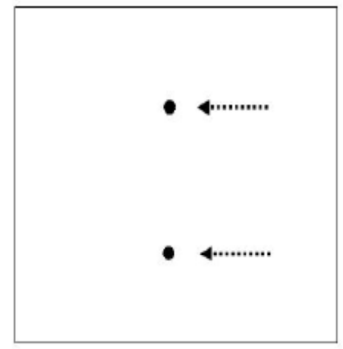

B-

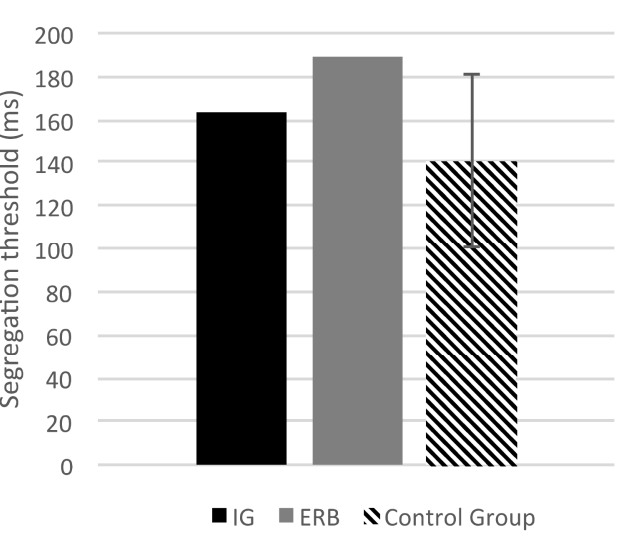

Figure 6: (A) Schematic representation of the visual stream segregation procedure (Experiment 3). The dotted arrows symbolise the one-stream (longer SOAs) or two stream (shorter SOAs) conditions. (B) Segregation threshold for IG (black), ERB (grey) and the controls (hatch) in milliseconds. The standard error bars are provided for the control group.

Results: The segregation thresholds (Figure 6B) were estimated at $141.1 \mathrm{~ms}(\mathrm{SD}=40.4)$ in the young adult healthy participants. The segregation thresholds of IG (threshold=163.9 $\mathrm{ms}$; $\mathrm{t}_{\text {modified }}=-0,59$ ) and ERB (threshold $=189.79 \mathrm{~ms} ; \mathrm{t}_{\text {modified }}=-0.51$ ) did not differ significantly from those of the controls and they did not differ between ERB and IG $\left(t_{\operatorname{modified}(18)}=-0.45\right.$; $\mathrm{p}=0.33$ ).

\subsubsection{Experiment 5: Attentional Blink}

Participants: IG, ERB and a RA-matched control group of 18 children who were 10 year 3 month old on average (mean $=123.72, S D=6.14$ ) and had a normal reading age (mean = 123.83, $S D=11.99$ ).

Stimuli: The stimuli were black or red digits (from 0 to 9; Arial font) that subtended a visual angle of $0.7^{\circ} \times 0.7^{\circ}$ at a viewing distance of $60 \mathrm{~cm}$. They appeared on a grey background (red: 192; green: 192; Blue: 192). The digits were displayed at the center of the computer screen in rapid serial presentation. Each digit was presented $40 \mathrm{~ms}$ and was followed by a grey screen for $60 \mathrm{~ms}$ before the onset of the next digit, thus yielding a stimulus rate of 10 items/second. Each trial consisted of a sequence of 15, 19 or 23 digits which included a single red digit that was either a 1 or a 5 ( $50 \%$ probability). 
Procedure: The procedure from Lallier et al. (2010) is illustrated on Figure 7A. Two conditions were proposed, a dual and a single conditions. In the dual condition of attentional blink, the participants had to identify a first target (T1), then detect a second target (T2). The red digit ("1" or " 5 ") was the T1 target to be identified. T1 occurred in all the sequences but could appear with the same probability in the $7^{\text {th }}, 11^{\text {th }}$ or $15^{\text {th }}$ position. The black digit "0" was the T2 target to be detected. T2 was presented at varying time intervals following T1, from lag $1(\mathrm{SOA}=100 \mathrm{~ms}$, T2 immediately follows $\mathrm{T} 1)$ to lag $7(\mathrm{SOA}=700 \mathrm{~ms}, 6$ intervening digits). T2 was present in half of the trials. In the single condition, there was no T1 targets and the participants only had to detect the black digit "0" when present. The single condition was designed to ensure that participants could accurately process a single target (T2) when presented in a stream of rapidly presented stimuli. Variations in the drop of performance according to T2 temporal position was taken as an index of the attentional blink. Each participant completed two successive blocks of 84 trials, the single task block first, then the dual task block. A practice of 15 trials was proposed before the single task condition. The experiment was administered in a dimly lit room, using E-Prime software on a PC computer (computer screen $=17$-in.; refresh rate $=85 \mathrm{~Hz}$ ). Each trial was initiated by a fixation cross, presented for $500 \mathrm{~ms}$ at the centre of the screen. The sequence of stimuli began $100 \mathrm{~ms}$ after the fixation cross offset. After each trial, the participant had to report orally whether T2 was present or not for the single condition and to name the red digit ("1" or "5") and report whether T2 was present or not in the dual condition. The experimenter initiated the next trial by pressing the space bar on the keyboard. No feedback was given during the experimental trials.

A-

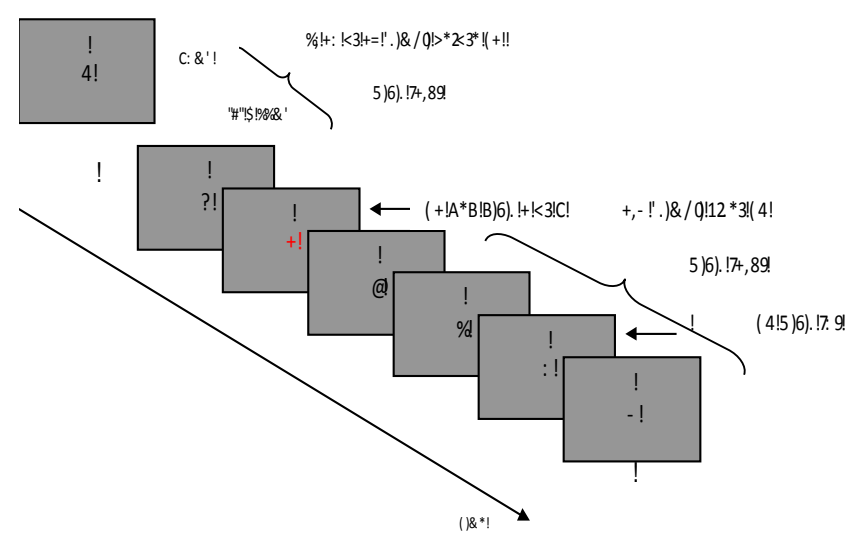

B-

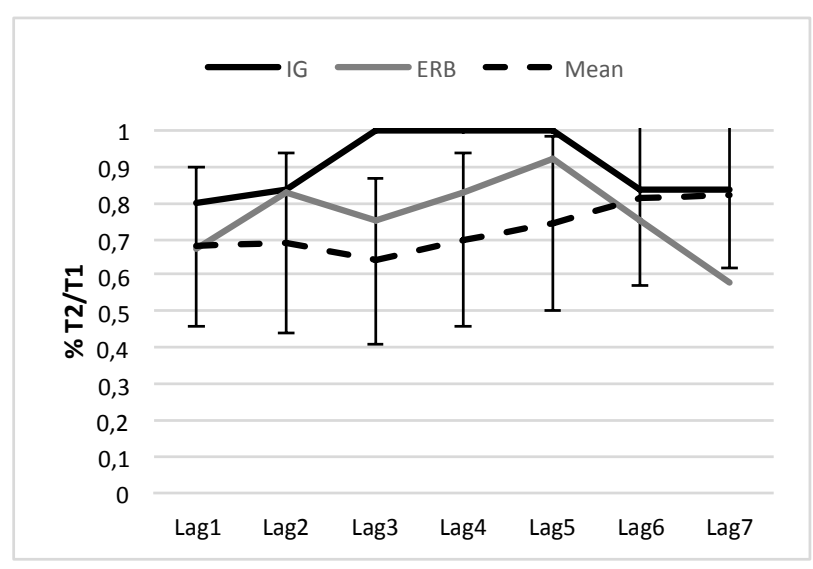

Figure 7: (A) illustration of the Attentional Blink protocole (Experiment 4); (B) Performance of IG (black line), the control group (dotted line) and ERB (grey line) in the dual condition. For the controls, standard error bars are depicted for each lag.

Results: Target detection accuracy was high in the single condition for IG (M $\left.\mathrm{M}_{\mathrm{IG}}=100 \%\right)$, ERB $(M=86,9 \%)$ and the control participants $(M=84 \%, S D=14,33)$ with no significant difference between IG and ERB ( $\left.t_{\text {modified(17) }}=0.65 ; p=0.26\right)$. IG performed at ceiling and her performance did not differ from that of the controls at any lag (all ts modified $>.05$ ), showing very good ability to identify a target within rapid serial presentation. For the $A B$ assessment in the control group, an analysis of Variance (ANOVA) with condition (single, dual) and lag (1, 2, 3, 4, 5, $6,7)$ as within-subjects factors was carried out on T2 detection rate when T1 was correctly 
identified. The results are provided on Figure 7B. The controls demonstrated a trend for a Condition by Lag interaction $(F(6 ; 102)=2.036, p=.067)$, suggesting an attentional blink. Planned comparisons (with Bonferroni correction) showed that they were less prone to identify the target in the dual than in the single condition at lag $1(F(1,17)=10,65$; $\mathrm{p}=0,005)$, lag $3(\mathrm{~F}(1,17)=8,83 ; \mathrm{p}=0,0085)$ and lag $4(\mathrm{~F}(1,17)=11,13 ; \mathrm{p}=0,0039)$. The controls showed a lag-2 sparing. Overall, the performance of the controls was characterized by an attentional blink during a time window of $100-400 \mathrm{~ms}$ after T1 presentation. The performance of IG (Figure 7B) did not differ significantly from that of the controls in any T2 temporal position (all ts modified non-significant). In the same way, ERB performed as the controls (all modified t-tests non-significant).

To investigate the duration of the $A B$ exhibited by IG, her dual condition performance was compared to the single condition performance of ERB and the controls at each lag. IG showed a performance similar as the controls and ERB performance (all ps>.05), which was also found for ERB. Lastly, in order to determine any $A B$ depth deficit in IG, we computed the difference between the single and dual condition on T2 detection at each lag for each control participant, for ERB and for IG. The attentional blink depth was similar in IG, ERB and the controls at any lag (all modified t-tests non-significant).

\subsection{Spatial Attention Shifting}

\subsubsection{Experiment 6 : Exogenous Orientation of Spatial Attention}

Participants: Twenty-six children participated as controls. They were 10 year 10 month old on average (Mean $=130.11, S D=3.65)$ for a reading age of 12 years on average (mean= 144.46; $\mathrm{SD}=16.61$ ).

Procedure: As shown on Figure 8, each trial started with a fixation cross displayed at the centre of the computer screen for $500 \mathrm{~ms}$. Two circles $\left(2.5^{\circ}\right.$ diameter $)$ were then simultaneously displayed for $500 \mathrm{~ms}$ at $8^{\circ}$ of eccentricity from the fixation point in the left and right visual fields. The rapid offset/onset $(40 \mathrm{~ms})$ of one of the two circles was used as a peripheral cue to attrack attention randomly to the left or right circle. The target to be detected was presented after two possible inter-stimulus intervals: ISI=60ms (SOA=100ms) or $|S|=160 \mathrm{~ms}(S O A=200 \mathrm{~ms})$. The target was a dot $\left(0.5^{\circ}\right)$ displayed for $40 \mathrm{~ms}$ at the center of one of the two circles. The peripheral cue was either valid (corresponding to the location of the following target; $50 \%$ of the trials) or invalid. Stimuli were white on a black background and had a luminance of $24 \mathrm{~cd} / \mathrm{m}^{2}$. Catch trials in which no target was presented were intermingled with the response trials.

The participants were seated $50 \mathrm{~cm}$ from the monitor with their head in a chin rest. They were asked to respond as fast as possible to the occurrence of the target by pressing the spacebar on the keyboard with their right hand. The maximum time allowed for response was $1500 \mathrm{~ms}$. The task began with 6 training trials. The experimental session consisted of 80 trials: 64 experimental trials (50\%Valid, 50\%Invalid), 16 catch trials (8 left and 8 right, $50 \% 100 \mathrm{~ms}, 50 \% 200 \mathrm{~ms} \mathrm{SOA}$ ). 


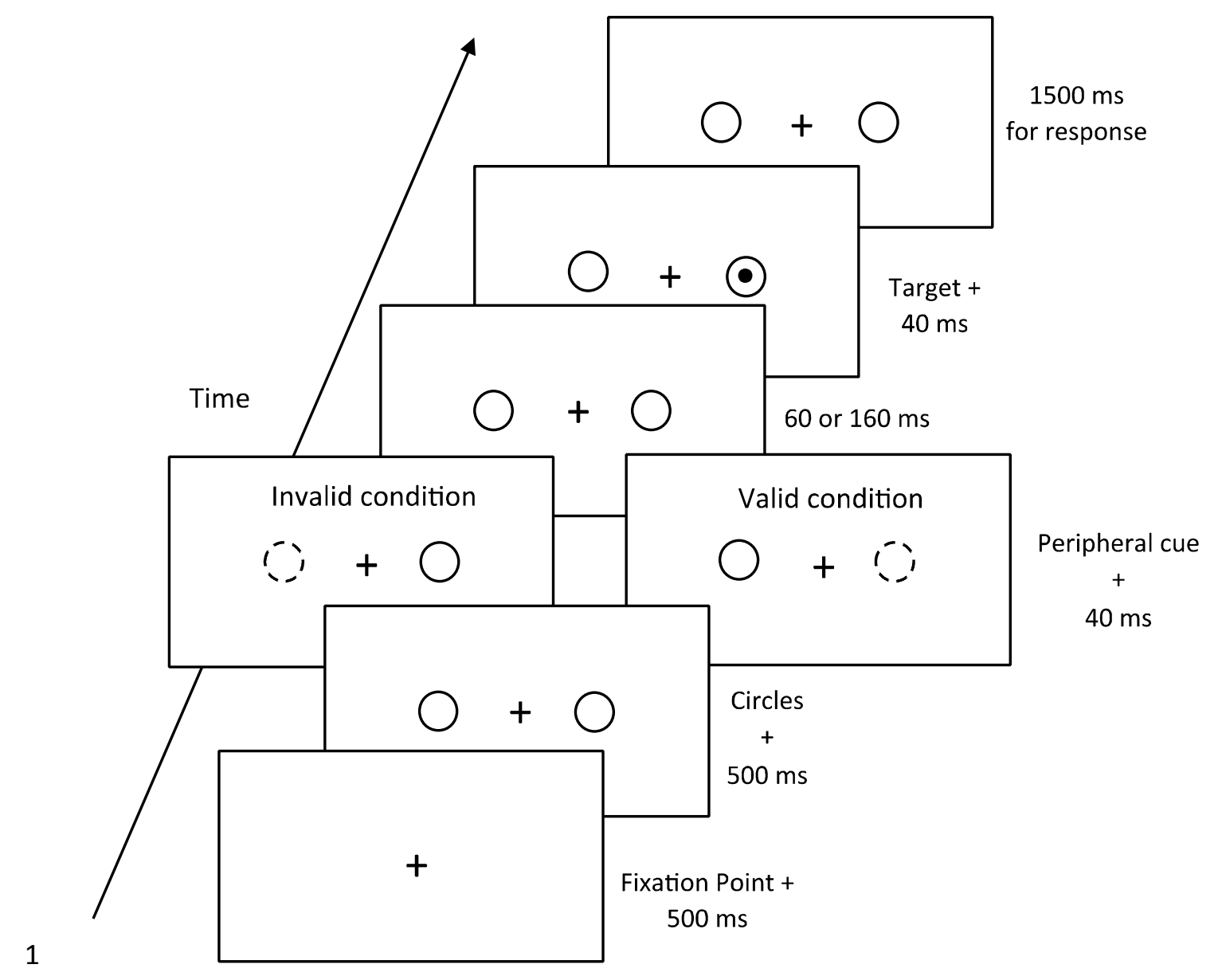

Figure 8: Procedure of the exogenous spatial attention task (Experiment 5).

Results: RTs for ERB, IG and the controls depending on the SOA and Cue Condition are provided on Figure 9. A multifactorial ANOVA was performed on the control group RTs with SOA (100ms vs. $200 \mathrm{~ms}$ ) and Cue Condition (valid vs. invalid) as within-subjects factors. There was a significant main effect of Cue Condition $(F(1,25)=65,033 ; p<.05)$, showing that targets were detected faster when presented after a valid cue (mean $\mathrm{RT}_{\text {valid }}=300.41$ $\mathrm{ms}, \mathrm{SD}_{\text {valid }}=28,77$ vs. mean $\left.\mathrm{RT}_{\text {invalid }}=335.34 \mathrm{~ms}, \mathrm{SD}_{\text {invalid }}=36,05\right)$. The $\mathrm{SOA}$ by Cue Condition interaction was significant $(F(1,25)=19,40 ; p<.002)$. The validity effect was larger for a $100 \mathrm{~ms}$ SOA than for a $200 \mathrm{~ms}$ SOA (validity effect $100=-46.65 \mathrm{~ms}, \mathrm{SD}=22.85$ vs. validity effect $200=-23.19 \mathrm{~ms}, \mathrm{SD}=27.75$ ), suggesting an automatic engagement of exogenous attention followed by a progessive disengagement. There was no significant main effect of $S O A(F<1)$.

IG and ERB exhibited similar validity effects at both the 100ms SOA (controls' mean = $46.65 \mathrm{~ms}, \mathrm{SD}=22.85 \mathrm{~ms}$; validity effect in $\mathrm{IG}=-61.625 \mathrm{~ms}$ vs. $E R B=-35.125 \mathrm{~ms}, p>0.05$ with $\mathrm{t}_{\text {modified }}(25)=0.21$ ) and the $200 \mathrm{~ms}$ SOA (control mean $=-23,19, \mathrm{SD}=27.75 \mathrm{~ms}$; validity

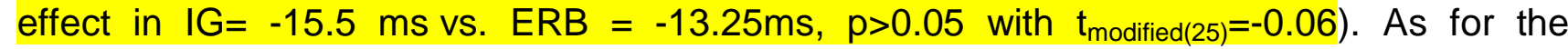
controls, the validity effect of patient IG decreased with increasing SOA, indicating normal engagement of exogenous attention (better at $100 \mathrm{~ms}$ than $200 \mathrm{~ms}$ ) after bilateral SPL damage. The index of temporal decrease (validity effect at $100 \mathrm{~ms} \mathrm{SOA}$ minus validity effect at $200 \mathrm{~ms} \mathrm{SOA}$ ) was computed for each participant. This index did not differ between IG and ERB $\left(\left(\mathrm{IG}=-46.13 \mathrm{~ms}\right.\right.$; Controls $=-23.46 \mathrm{~ms}, \mathrm{SD}_{\text {control }}=26.63 \mathrm{~ms}$; $E R B=-21.88 \mathrm{~ms}$, $p>0.05$ with $t_{\text {modified(25) }}=-0.64$ ). 


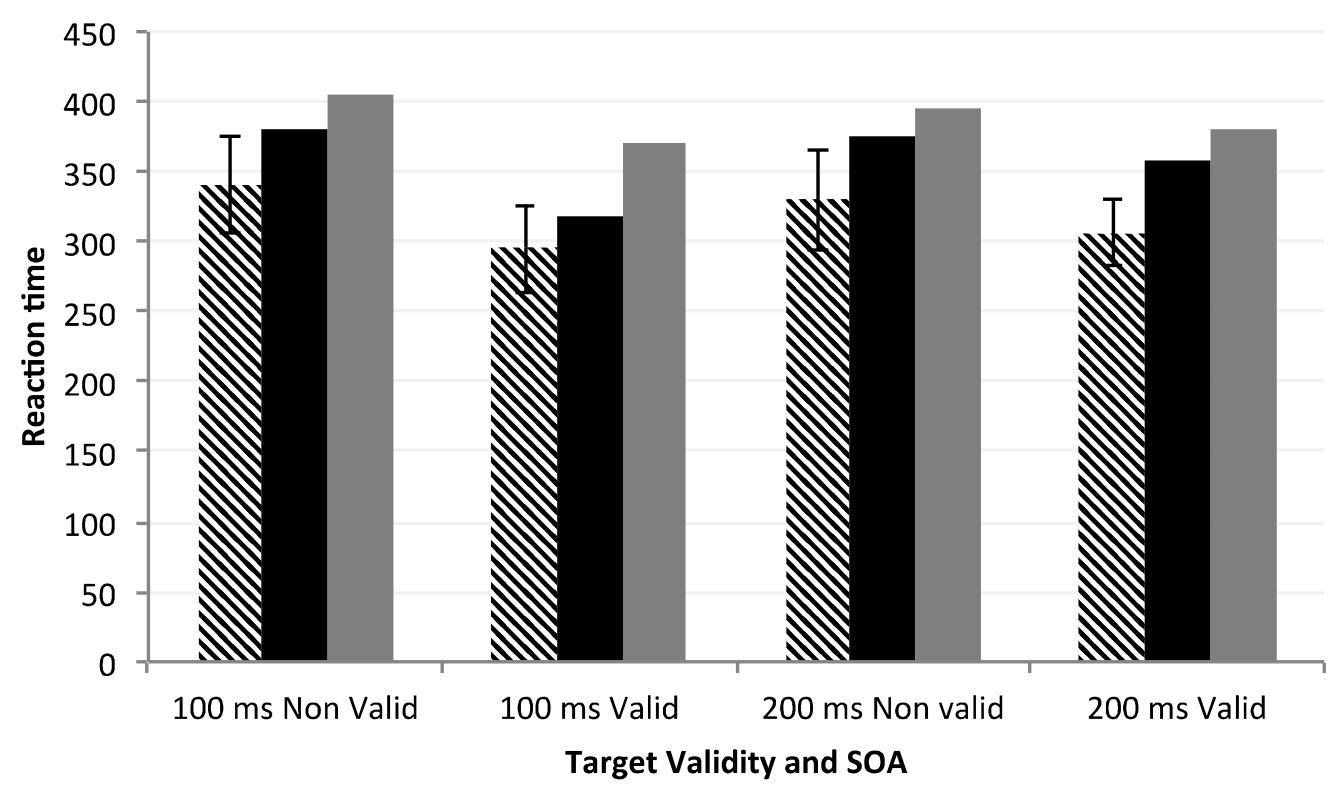

1

2 Figure 9: Mean reaction times in target detection for the two exogenous conditions of cueing 3 (valid or invalid) and SOA (100 ms or $200 \mathrm{~ms}$ ) for the control group (hatch), IG (black) and $4 \quad$ ERB (grey). Standard error bars are depicted for the control group.

\subsubsection{Experiment 6 : Endogenous orientation of spatial attention}

Participants: IG, ERB and a control group of 71 healthy young adults (mean age $=19.8$ years) whose performance on the voluntary orienting task was taken from a previous study (Striemer et al. 2007) participated in Experiment 6.

Stimuli and procedure: A 80\% predictive central arrow cue was used for voluntary orienting. Some targets were presented without cues to examine response times for simple target detection. Target location was indicated by green circles subtending $2^{\circ}$ of visual angle, presented $12^{\circ}$ left and right of fixation (see Figure 10). The target was a red circle presented within one of the green circles. The coloured stimuli were presented on a white background. After a stimulus onset asynchrony (i.e. time between cue and target onset; SOA) of 300 or $500 \mathrm{~ms}$, targets appeared at the cued (valid) or uncued (invalid) location. The participants responded by pressing a button with the right hand on the keyboard. They were seated $50 \mathrm{~cm}$ from the monitor with their head in a chin rest. For patient IG and her control ERB, a longer SOA (800 ms) was additionally tested.

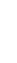

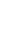
22 


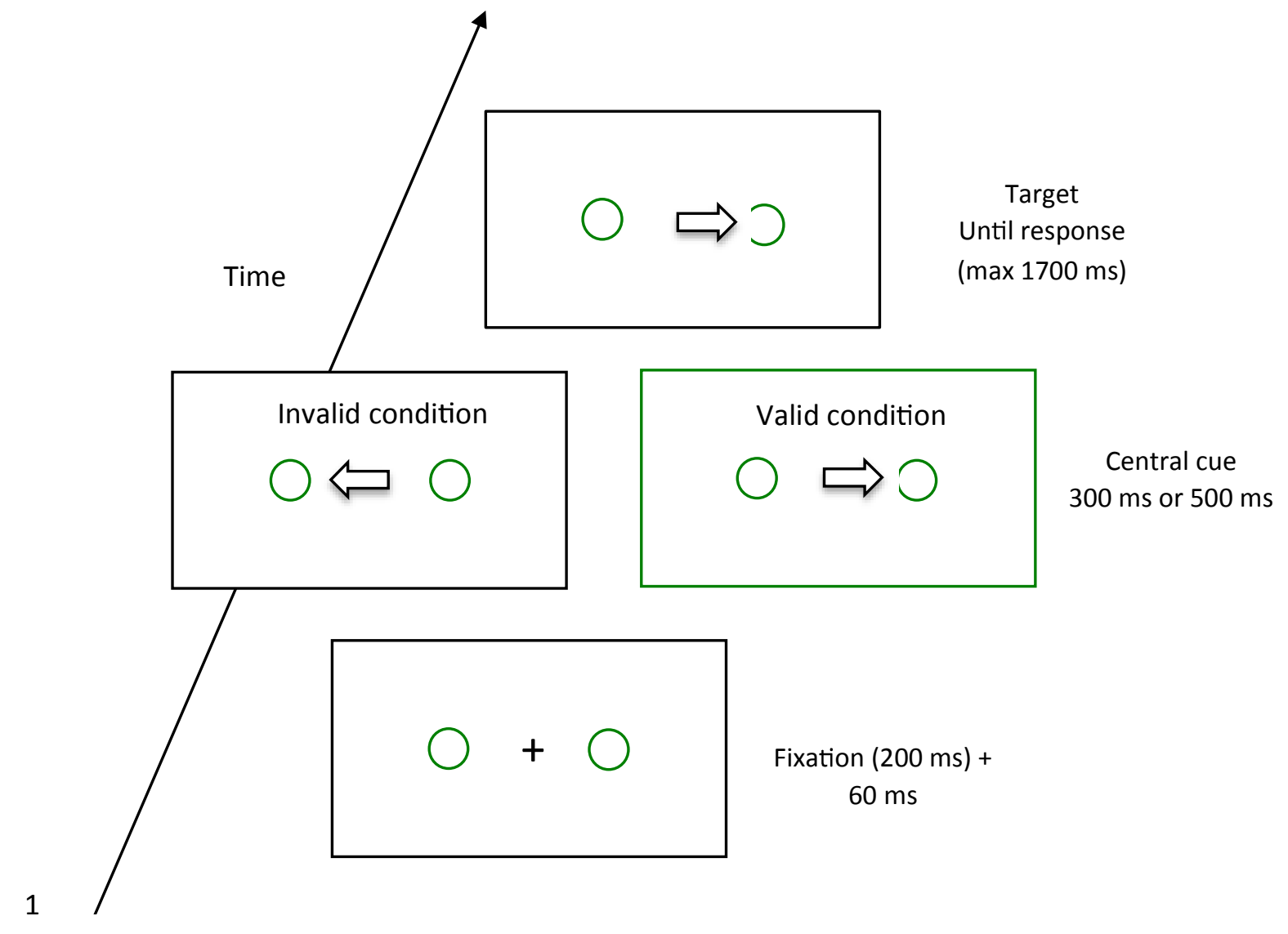

2 Figure 10: Procedure of the endogenous condition of visual attention orientation.

4 Results : Reaction times for target detection in the endogenous condition are provided on 5 Figure 11 for IG, ERB and the control group.

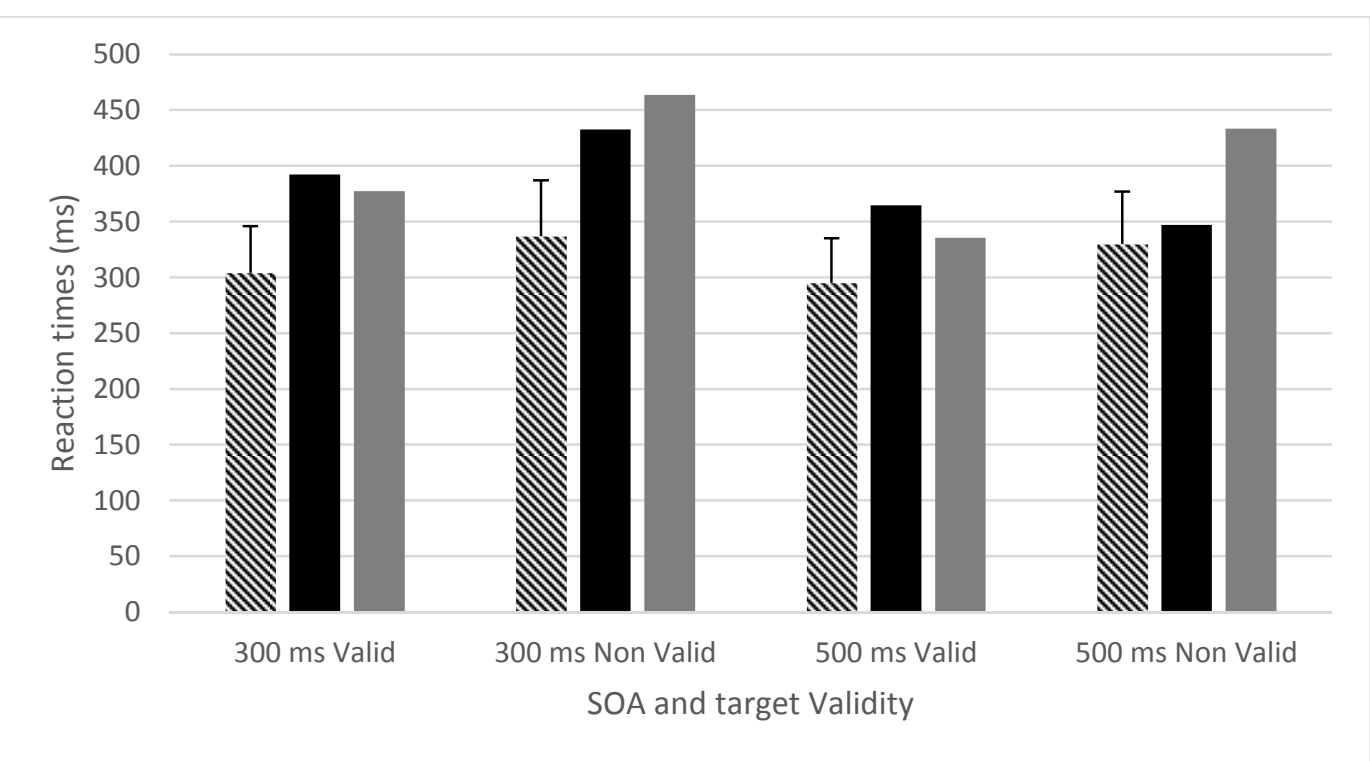

7 Figure 11: Mean reaction times for target detection in the endogenous condition of spatial 8 orientation (Experiment 6) depending on cue condition (valid or invalid) and SOA (300 ms or $9500 \mathrm{~ms}$ ) for IG (black), the control group (hatch), and ERB (grey). 
The ANOVA performed on the control RTs showed main effects of SOA and cue condition $(F>12, p<0.05)$. RTs were faster in the long compared to the slow SOA and in the valid compared to the invalid cueing condition. There was no significant SOA by Validity interaction $(F(1,70)=0.4 ; p>0.05)$, showing that, contrary to the exogenous condition, the validity effect was constant in time in the context of endogenous attention.

Contrary to the control group and ERB, IG was slower at detecting the target in the valid than the invalid condition at the $500 \mathrm{~ms}$ SOA, which suggests an inhibition of return. Actually, IG and ERB exhibited different validity effects at both $300 \mathrm{~ms}$ SOA (controls' mean $=-32.88 \mathrm{~ms}, \mathrm{SD}=18.00$; validity effect in $\mathrm{IG}=-40.64 \mathrm{~ms}$ vs. $E R B=-86.0 \mathrm{~ms}, p<0.05$ with $t_{\text {modified(70) }}=1.78$ ) and $500 \mathrm{~ms} S O A$ (control mean $=-34.57 \mathrm{~ms}, \quad S D=17.67$; validity effect in $\mathrm{IG}=17.30 \mathrm{~ms}$ vs. $\mathrm{ERB}=-98 \mathrm{~ms} ; \mathrm{p}<0.05$ with $\left.\mathrm{t}_{\text {modified }}(70)=4.6, p<0.05\right)$. The index of temporal decrease (validity effect at $300 \mathrm{~ms}$ SOA minus validity effect at $500 \mathrm{~ms}$ SOA) was computed for each participant. IG exhibited a pathological decrease of the validity effect between 300 ms --where invalidly cued targets were detected slower than validly cued targets-- and 500 ms --where she showed an inhibition of return suggesting that she could not maintain her attention voluntarily as long as the controls and $\mathrm{ERB}\left(\mathrm{M}_{\text {controls }}=1.54 ; \mathrm{SD}_{\text {controls }}=20.66 ; \mathrm{G}_{\text {index }}\right.$ of decrease $=-58.3 ; \mathrm{ERB}_{\text {index of decrease }}=12.0, \mathrm{p}<0.05$ with $\left.\mathrm{t}_{\text {modified }(70)}=-2.41\right)$.

This temporal aspect of endogenous attention deficit was confirmed by an additional testing of patient IG --and comparison with ERB-- at a longer $(800 \mathrm{~ms}) \mathrm{SOA}$. Results are presented on Figure 11. Contrary to ERB, IG did not benefit from the $80 \%$ valid cues. She did not show faster reaction times for the valid than the invalid condition (IG validity effect=8.5 ms) while ERB exhibited a large validity effect (ERB validity effect=-108 ms).

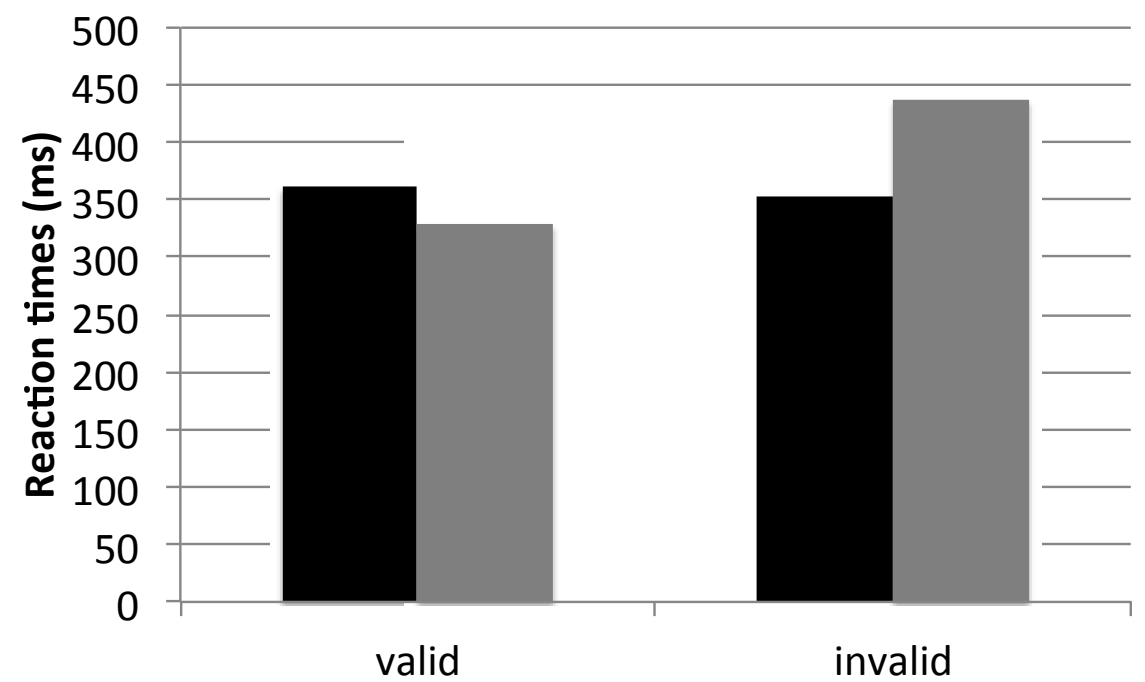

Cueing conditions

Figure 12: Reaction times of IG (black) and ERB (grey) in the valid and invalid cueing conditions of endogenous attention (Experiment 6 ) for an SOA of $800 \mathrm{~ms}$.

\section{Discussion}


IG, a bilateral SPL damaged patient, performed a series of visual attention tasks that assessed the different facets of visual attention for which dyslexic participants have been shown to exhibit a deficit. Our main goal was to provide new insights on the facets of visual attention that specifically relate to the superior parietal lobules. We reasonned that evidence for deficits on the whole set of tasks in IG would support the existence of a single attentional system related to a single neural network that includes the SPLs. As a direct consequence, such a unitary account would predict that children with developmental dyslexia would show simultaneous deficits on all types of tasks and that the visual attention deficits reported in the dyslexic population do reflect a single visual attention dysfunction, as sometimes suggested (Facoetti et al., 2006; Vidyasagar \& Pammer, 2010). On the contrary, evidence for a dissociation between two subsets of preserved vs. impaired VA tasks in IG would clarify the type of visual attention skills that specifically relate to the SPLs. Such dissociation would support the existence of at least two attentional systems that relate to distinct neural substrates. As a consequence, dyslexic children might show selective impairment of one or the other attentional network. We could further expect these selective impairments to be associated with distinct cognitive deficits in developmental dyslexia.

IG was first administered tasks of VA span (Experiment 1 and 2). In Experiment 1, she was presented with briefly displayed 5-consonant strings in conditions of global and partial report. In both conditions, her performance was far poorer than that of the controls, showing that she could only identify a few consonants when simultaneously presented within 5consonant strings. To better grasp the severity of her disorder, sequences of 3,4 and 5 consonants were administered in Experiment 2 but in the global report condition only. Results showed that her very poor performance extended to shorter strings of 3 and 4 consonants. Her poor performance on these two tasks of simultaneous multi-letter processing (Experiment 1 and 2) contrasted with her very good report performance on similar strings of five letters when presented sequentially in Experiment 3. IG performed at the level of ERB and the controls on this later task and showed a similar response pattern. She was quite good at processing letters when briefly presented one at a time, thus showing that her poor performance on the VA span tasks (Experiment 1) can not be attributed to poor oral report skills, poor single letter processing or poor verbal short-term memory. A similar dissociation --poor multi-letter simultaneous processing but good multiletter sequential processing-was previsouly reported in VA-span-impaired dyslexic children (Lassus-Sangosse et al., 2008; Valdois et al., 2011). 
IG's poor performance on the VA span tasks is well in line with previous evidence for a SPLs dysfunction in children with VA span dyslexia (Lobier et al., 2014; Peyrin et al., 2011, 2012; Reilhac et al., 2013). Like IG, dyslexic children with SPL bilateral dysfunction show poor performance in global and partial report tasks despite fast and normal single letter processing. In line with previous neuroimaging data in healthy (Lobier et al., 2012) and dyslexic (Lobier et al., 2014) individuals, the current findings confirm that the SPLs are involved in multi-element (here letters, but true for non-alphanumaric characters as well, Lobier et al., 2012, 2014) visual processing but not in the processing of the same elements when presented in isolation.

Although our previous studies on developmental dyslexia mainly used sequences of 5 (or 6) items, other studies reported poor processing for shorter 4-digit strings in dyslexic children (Hawelka \& Wimmer, 2005). The present findings show that a damage of the SPLS yields poor performance for even shorter letter strings. They suggest that future studies should explore VA span skills in dyslexic children more in depth, through systematic variations of string length.

Experiment 2 further assessed whether performance was sensitive to lateral interference between adjacent letters, or crowding (Gori \& Facoetti, 2015; Martelli et al., 2009; Whitney \& Levy, 2010). The classic global and partial report tasks have been initially designed to minimize potential crowding effects by systematically increasing interletter spacing. To ensure that poor performance on VA span tasks in Experiment 1 was not just the consequence of very severe crowding, spacing between letters was drastically increased in the large spacing condition of Experiment 2. IG showed poor performance irrespective of spacing for the 3 and 4 letter strings. A spacing effect was observed for 5 -letter strings but showed an advantage for the small spacing condition, against any crowding interpretation. The overall findings suggest that IG's poor performance on VA span tasks is free from lateral interference and primarily reflects a difficulty to process multiple letters within strings. Another important consequence of the current findings is that bilateral SPL damage did not yield larger crowding effect, thus suggesting that the SPLs are not involved in crowding.

In Experiment 4 and 5, IG was administered tasks of stream segregation and attention blink to assess her temporal attention shifting skills. In Experiment 4, stream segregation threshold - corresponding to the inter-stimulus interval for which the participants could not decide whether they perceived one or two visual streams - was estimated. The segregation threshold was found similar in IG and the controls, showing that she had no difficulty to quickly engage her visual attention on a stimulus and disengage it automatically to process 
the following one. Her preserved temporal attentional shifting skills were confirmed in Experiment 5, in which IG showed similar attentional blink duration and similar attention blink depth as the controls. Overall, these findings demonstrate preserved temporal attention shifting in IG despite a severe VA span deficit. A dissociation between VA span and temporal attention shifting was previously reported in a case study of developmental dyslexia (Lallier et al., 2010c). Evidence for the absence of correlation between visual stream segregation threshold and VA span in children with developmental dyslexia further supports the independence of the two underlying attentional systems (Lallier et al., 2009; see also Lallier \& Valdois, 2012).

Spatial attention shifting skills were explored in the two last experiments. In the exogenous cueing condition of spatial attention (Experiment 6), IG showed a validity effect of the same amplitude as the controls. She detected the target faster when the peripheral cue attracted her attention toward the target location (valid condition), showing that she was quite efficient at engaging attention on the right or left visual field following exogenous cueing. In contrast, her performance was rather atypical in the endogenous condition of spatial attention (Experiment 7). In this experiment where a central arrow pointing left or right indicated the location of the upcoming target with $80 \%$ predictive power, the controls showed faster responses and a stronger validity effect at longer SOAs. A validity effect was only found at the shorter (300 ms) SOA in IG but not for longer SOAs (500 and $800 \mathrm{~ms}$ ), suggesting that she was unable to maintain her attention voluntarily as long as the controls. Many studies have reported a deficit in exogenous cueing in developmental dyslexia (Facoetti et al., 2005, 2010b; Roach \& Hogben, 2004; Ruffino et al., 2014) or at risk pre-readers (Facoetti et al., 2010a; Franceschini et al., 2012) but the results were less consistent with respect to endogenous cueing in the few studies that assessed the two cueing conditions in the same participants (Facoetti et al., 2000, 2006). Reversely, a deficit specific to the endogenous cueing condition was emphasized in Chinese dyslexic children in the absence of exogenous spatial attention deficit (Liu, Liu, Pan \& Xu, 2018). An additional key point here is strong evidence in support of distinct anamo-functional attentional systems supporting endogenous (goal-driven) vs. exogenous (stimulus-driven) spatial attention (Chica et al., 2013).

Overall, the present study provides strong evidence for the existence of distinct attentional systems that rely on distinct neural substrates. The exploration of IG visual attention skills clearly shows that bilateral superior parietal lobule damage does not result in a severe and general visual attention deficit but rather affects some specific dimensions of visual attention. IG shows impaired performance in VA span tasks of multi-element simultaneous 
processing and in the endogenous condition of spatial attention shifting but preserved skills in tasks of temporal attention shifting and exogenous spatial cueing. These findings strongly support the existence of distinct attentional systems, one of which involves the SPLs, themselves part of the dorsal attentional network-DAN (Chica et al., 2013; Corbetta \& Shulman, 2002). They help clarifying the pattern of results reported in the scientific literature on developmental dyslexia. Deficits of VA span and temporal and spatial attention shifting have consistently been reported in individuals with DD but no study explored all three facets of visual attention in the same participants, so that the question remains whether this constellation of attentional deficits is systematically associated (or not) in the dyslexic population. The current findings clearly suggest that selective deficits of VA span and endogenous spatial cueing should characterize a first subset of dyslexic children who shows a bilateral SPL dysfunction while at least a second subset might show selective deficit of temporal attention shifting and exogenous spatial attention.

Such a dichotomy is consistent with the hypothesis put forward by Lallier \& Valdois (2012) regarding the independence of the VA span theory (Bosse \& Valdois, 2007) and the sluggish attentional shifting (SAS, Hari \& Renvall, 2001) theory of developmental dyslexia, two theoretical accounts that further dissociate with respect to the contribution of visual attention difficulties to phonological deficits. On one hand, a large body of research shows that VA span and phoneme awareness deficits typically dissociate in developmental dyslexia (Bosse et al., 2007 ; Germano et al., 2014 ; Lallier et al., 2010c ; Zoubrinetzky et al., 2014 ; See Saksida et al., 2016 for contradictory results and Reilhac et al., submitted, for a response) and that VA span and phoneme awareness are independent unique predictors of reading performance in typical readers (Bosse \& Valdois, 2009 ; Lobier et al., 2013 ; Valdois et al., submitted; van den Boer et al., 2013). On the other hand, sluggish temporal attentional shifting typically cooccurs with phonological deficits in individuals with developmental dyslexia (Lallier et al., 2009, 2010a, 2010b, 2010c) and exogenous spatial attention deficits were reported in only a subgroup of dyslexic children with very poor pseudo-word reading and poor phonological skills (Facoetti et al., 2010; Ruffino et al., 2014; see however, Banfi, Kemény, Gangl, Schulte-Körne, Moll \& Manderl, 2017). We would thus expect the first subset of dyslexic children with SPLs dysfunction to show poor VA span, atypical spatial endogenous attention but preserved phonological skills while dyslexic children with poor temporal attention shifting and poor exogenous spatial attention would be further impaired in phonological processing. Some recent findings further suggest that the latter but not the former would show a categorical perception deficit (Zoubrinetzky et al., 2016). 
The current findings also provide new insights on potential association/dissociation with an asymmetric distribution of attention between the left and right hemifields --or minineglect-and atypical performance in visual search tasks depending on dyslexia subtypes. Interhemispheric asymmetries have been searched for in developmental dyslexia and sometimes reported (Facoetti \& Molteni, 2001; Facoetti \& Turatto, 2000; Hari, Renvall \& Tanskanen, 2001; Sireteanu et al., 2005). However, some case studies of dyslexic children with a VA span deficit failed to report any asymmetry between the left and right visual hemifields (Dubois et al., 2010; Valdois et al., 2011). IG's results are quite in line with these later reports, showing that a bilateral SPL damage does not yield visuo-spatial neglect. These findings are in line with the current litterature on the neural substrates of spatial attention and unilateral spatial neglect. Lesions of the ventral attentional network-VAN -in particular the right temporo-parietal junction-- and not of the dorsal attentional network-DAN, are traditionnaly associated with unilateral spatial neglect (Chica et al., 2013; Mort et al. 2003; Vallar \& Perani, 1987). Moreover, although the VAN and DAN are known to interact, this interaction is not symetrical. Recent neuroimaging results suggest that a structural lesion of the VAN affects the functioning of the DAN (Corbetta et al. 2005) while conversely a lesion of the DAN produces restricted deficits of spatial attention (Gillebert et al. 2011, Shomstein et al. 2010) with features of Balint syndrome (e.g. visual disorientation, deficits of global perception, shape identification in a cluttered field, see Pisella et al., 2015, 2013), ressembling more to VA span dyslexia than the clinical picture of spatial deficits in neglect. The current findings are further in line with evidence that the right-hemispheric regions of the VAN are specifically involved in exogenous covert shifting of spatial attention, towards both the left and right visual hemifields whereas the DAN is involved in the spatial selection of objects for voluntary shifting of overt and covert attentional exploration (Chica et al., 2011; Corbetta et al., 2000; Corbetta \& Shulman, 2011; Hopfinger et al., 2000; Kastner et al., 1999).

IG's lesion matches the parietal regions of the DAN. She has been previously studied in visual search and shows a reduced visuo-attentional window specifically when she faces stimuli made by a combination of lines (Khan et al., 2016). This deficit in visual search after bilateral SPL damage is in line with the impaired search performance specific to « multifeatures shapes » combining separable features previously reported in poor readers (Casco \& Prunetti, 1986) and with evidence for a visual search deficit in VA span impaired dyslexic children (Lallier et al., 2013).

\section{Conclusion}


Exploration of distinct facets of visual attention in patient IG, who suffers a bilateral SPL lesion, supports the existence of distinct attentional systems that relate to distinct neural substrates. IG shows a lesion of the DAN yielding to poor multielement simultaneous processing (i.e. poor VA span) and poor endogenous spatial attention while temporal attention shifting and exogenous spatial attention are intact, showing that they relate to a distinct attentional network, quite probably the VAN. Exploration of patient IG further provides new insights on developmental dyslexia. A bilateral SPL dysfunction has been reported in a subset of dyslexic children who show poor VA span but preserved phonological skills. In line with the current findings, these dyslexic individuals are free from sluggish temporal attention shifting but impaired in visual search. They should further show impaired endogenous but preserved exogenous spatial attention, which remains to be systematically investigated. In contrast, the current findings suggest that the exogenous spatial attention and temporal attention shifting deficits reported in developmental dyslexia, actually defines another subset of dyslexic individuals who show associated phonological deficits but preserved VA span and might be more prone to show a left-right hemifield asymetry in tasks of spatial processing. While the temporal and spatial attentional functions of the VAN and the DAN are both involved in the development of reading, we argue that they should nevertheless be distinguished. Evidence from IG allows making new predictions about developmental dyslexia, which will help clarifying the role of each attentional subsystem on reading acquisition and the consequences of a selective deficit of one or the other attentional system in developmental dyslexia.

\section{References}

Banfi, C, Kenény, F., Gangl, M., Schulte-Körne, G., Moll, K. \& Landerl, K. (2017). Visuaospatial cueing in children with differential reading and spelling profiles. Plos One, 12 (7):e0180358.

Bogon, J., Finke, K. \& Stenneken, P. (2014). TVA-based assessment of visual attentional functions in developmental dyslexia. Frontiers in Psychology, 5, 1172. doi: 10.3389/fpsyg.2014.01172

Bosse, M.L., Tainturier, M.J. \& Valdois, S. (2007). Developmental dyslexia: the visual attention span deficit hypothesis. Cognition, 104, 198-230.

Bosse, M.L. \& Valdois, S. (2009). Influence of the visual attention span on child reading performance: a cross-sectional study. Journal of Research in Reading, 32, 2, 230-253.

Boucard, M. \& Humphreys, G.W. (1992). The computation of conceptual structures from collinearity and closure: normality and pathology. Neuropsychologia, 30, 6, 527-546. 
Brannan, J. \& Williams, M. (1987). Allocation of visual attention in good and poor readers. Perception \& Psychophysics, 41, 23-28.

Buchholz, J. \& Davies, A. (2007). Attentional blink deficits observed in dyslexia depend on task demands. Vision Research, 47, 1292-1302.

Chica, A.B., Bartolomeo, P. \& Lupiáñez, J. (2013). Two cognitive and neural systems for endogenous and exogenous spatial attention. Behavioral Brain Research, 237: 107123.

Chica, A.B., Bartolomeo, P. \& Valero-Cabré., A. (2011). Dorsal and ventral parietal contributions to spatial orienting in the human brain. Journal of Neuroscience, 31, 22, 8143-8149.

Cooper, A.C.G., Humphreys, G.W., Hulleman, J., Praamstra, P. \& Georgeson, M. (2004). Transcranial magnetic stimulation to right parietal cortex modifies the attentional blink. Experimental Brain Research, 155, 24-29.

Corbetta, M., Kincade, M.J., Lewis, C., Snyder, A.Z. \& Sapir, A. (2005). Neural basis and recovery of spatial attention deficits in spatial neglect. Nature Neuroscience, 8, 16031610.

Corbetta, M., Kincade, J.M., Ollinger, J.M., McAvoy, M.P. \& Shulman, G.L. (2000). Voluntary orienting is dissociated from target detection in human posterior parietal cortex. Nature Neuroscience, 3, 3, 292-297.

Corbetta, M. \& Shulman, G.L. (2002). Control of goal-directed and stimulus-driven attention in the brain. Nature Reviews Neuroscience, 3, (3): 201-215.

Corbetta, M. \& Schulman, G.L. (2011). Spatial neglect and attention network. Annual Review Neuroscience, 34, 569-599.

Crawford, J.R., \& Garthwaite, P.H. (2002). Investigation of the single case in neuropsychology: Confidence limits on the abnormality of test scores and test score differences. Neuropsychologia, 40, 1196-1208.

Crawford, J. R. \& Garthwaite, P. H. (2006). Methods of testing for a deficit in single case studies: evaluation of statistical power by Monte Carlo simulation. Cognitive Neuropsychology, 23, 6, 877-904.

Crawford, J. R., Garthwaite, P. H. \& Wood, L.T. (2010). Infrential methods for comparing two single cases, Cognitive Neuropsychology, 27, 377-400.

Dubois, M., Kyllingsbaek, S., Prado, C., Peiffer, E., Lassus-Sangosse, D. \& Valdois, S. (2010). Fractionating the multi-element processing deficit in developmental dyslexia: Evidence from two case studies. Cortex, 46, 6, 717-738.

Eidelberg, D. \& Galaburda, A.M. (1984). Inferior parietal lobule: Divergent architectonic asymmetries in the human brain. Archives of Neurology, 41, 843-852 
Facoetti, A., Corradi, N., Ruffino, M., Gori, S. \& Zorzi, M. (2010a). Visual spatial attention and speech segmentation are both impaired in preschoolers at familial risk for developmental dyslexia. Dyslexia, 16, 226-239.

Facoetti, A., Lorusso, M. L., Cattaneo, C., Galli, R. \& Molteni, M. (2005). Visual and auditory attentional capture are both sluggish in children with developmental dyslexia. Acta Neurobiol. Exp. 65, 61-72.

Facoetti, A. \& Molteni, M. (2001). The gradient of visual attention in developmental dyslexia. Neuropsychologia, 39, 352-357.

Facoetti, A., Paganoni, P., Turatto, M., Marzola, V., and Mascetti, G. G. (2000). Visualspatial attention in developmental dyslexia. Cortex, 36,109-123.

Facoetti, A. \& Turatto, M. (2000). Asymmetrical visual fields distribution of attention in dyslexic: A neuropsychological study. Neuroscience Letters, 290, 216 - 218.

Facoetti, A., Turatto, M., Lorusso, M. L. \& Mascetti, G. G. (2001). Orienting of visual attention in dyslexia: evidence for asymmetric hemispheric control of attention. Experimental Brain Research, 138, 46-53.

Facoetti, A., Trussardi, A. N., Ruffino, M., Lorusso, M. L., Cattaneo, C., Galli, R. et al. (2010b). Multisensory spatial attention deficits are predictive of phonological decoding skills in developmental dyslexia. Journal of Cognitive Neuroscience, 22,1011-1025.

Facoetti, A., Zorzi, M., Cestnick, L., Lorusso, M. L., Molteni, M., Paganoni, P. et al. (2006). The relationship between visuo-spatial attention and nonword reading in developmental dyslexia. Cognitive Neuropsychology, 23, 841-855.

Fan, J., McCandliss, B.D., Sommer, T., Raz, A. \& Posner, M.I. (2002). Testing the efficiency and independence of attentional networks. Journal of Cognitive Neuroscience, 14, 3, 340-347.

Franceschini, S., Gori, S., Ruffino, M., Pedrolli, K. \& Facoetti, A. (2012). A causal link between visual spatial attention and reading acquisition. Current Biology, 22, 814-819.

Friedrich, F.J., Egly, R., Rafal, R.D. \& Beck, D. (1998). Spatial attention deficits in humans : a comparison of the superior parietal and temporal-parietal junction lesions. Neuropsychology. 1998, 12, 2, 193-207.

Gauthier, L., Dehaut, F. \& Joanette, Y. (1989). The Bells Test: A $\square$ quantitative and qualitative test for visual neglect. International Journal of Clinical Neuropsychology, 11, 49-54.

Germano, D.G., Reilhac, C., Capellini, A.S. \& Valdois, S. (2014). The phonological and visual bases of developmental dyslexia in Brazilian Portuguese. Frontiers in Educational Psychology 5, 1169.

Gillebert, C.R., Mantini, D., Thijs, V., Sunaert, S., Dupont, P. \& Vandenberghe, R. (2011). Lesion evidence for a critical role of the intraparietal sulcus in spatial attention. Brain, 134, 1694-1709. 
Godefroy O. \& le GREFEX (2008). Fonctions exécutives et pathologies neurologiques et psychiatriques: évaluation en pratique clinique. Marseille: Solal.

Gori, S. \& Facoetti, A. (2016). How the visual aspects can be crucial in reading acquisition? The intriguing case of crowding and developmental dyslexia. Journal of vision, 15, 1-20.

Gronwall, D. \& Sampson, H. (1974). The Psychological effects of concussion. Auckland University Press, Auckland, New Zeland.

Hari, R., \& Renvall, H. (2001). Impaired processing of rapid stimulus sequences in dyslexia. Trends in Cognitive Science, 5, 525-532.

Hari, R., Renvall, H. \& Tanskanen, T. (2001). Left minineglect in dyslexic adults. Brain, 124, 1373-1380.

Hari, R., Valta, M., \& Uutela, K. (1999). Prolonged attentional dwell time in dyslexic adults. Neuroscience Letters, 271, 3, 202-204.

Hawelka, S. \& Wimmer, H. (2005). Impaired visual processing of multiple-element arrays is associated with increased number of eye movements in dyslexic readers, Vision Research, 45, 855-863.

Hopfinger, J.B., Buonocore, M.H. \& Mangun, G.R. (2000). The neural mechanisms of topdown attentional control. Nature Neuroscience, 3, 284-291.

Khan, A.Z., Prost-Lefebvre, M., Salemme, R., Blohm, G., Rossetti, Y., Tilikete, C. \& Pisella, L. (2016) The attentional fields of visual search in simultanagnosia and healthy individuals: How object and space attention interact. Cerebral Cortex, 26, 3, 1242-1254.

Kastner, S., Pinsk, M.A., De Weerd, P., Desimone, R. \& Ungerleider, L.G. (1999). Increased activity in human visual cortex during directed attention in the absence of visual stimulation. Neuron, 22, 751-761.

Lallier, M., Donnadieu, S., Berger, C. \& Valdois, S. (2010c). A case study of developmental phonological dyslexia: Is the attentional deficit in rapid stimuli sequences processing amodal? Cortex, 46, 231-241

Lallier, M., Donnadieu, S., Thierry, G., Tainturier, M. J., Billard, C., Peyrin, C. et al. (2009). Auditory and visual stream segregation in children and adults: An assessment of the amodality assumption of the 'sluggish attentional shifting' theory of dyslexia. Brain Research, 1302, 132-147.

Lallier, M., Donnadieu, S. \& Valdois, S. (2010b). Visual attentional blink in dyslexic children: Parameterizing the deficit. Vision Research, 50, 1855-1861.

Lallier, M., Donnadieu, S. \& Valdois, S. (2013). Investigating the role of visual and auditory search in reading and developmental dyslexia. Frontiers in Human Neuroscience, 7, 597. doi: 10.3389/fnhum.2013.00597

Lallier, M., Tainturier, M. J., Dering, B., Donnadieu, S., Valdois, S. \& Thierry, G. (2010a). Behavioral and ERP evidence for amodal sluggish attentional shifting in developmental dyslexia. Neuropsychologia, 48, 4125-4135. 
Lallier, M. \& Valdois, S. (2012). Sequential versus Simultaneous processing deficits in developmental dyslexia. In T. Wydell \& L. Fern-Pollak (Eds.), Dyslexia: $A$ comprehensive and international approach. In Tech, DOI:10.5772/39042.

Lassus-Sangosse, D., N'Guyen-Morel, M.A. \& Valdois, S. (2008). Sequential or simultaneous visual processing deficit in developmental dyslexia. Vision Research, 48, 979-988.

Lefavrais, P. (1967). Test de l'Alouette. [The "Alouette" Reading Test.] Paris: Editions du Centre de Psychologie Appliquée.

Liu, S., Liu, D., Pan, Z. \& Xu, Z. (2018). The association between reading abilities and visual-spatial attention in Hong-Kong Chinese children. Dyslexia, 10.1002/dys.1584.

Lobier, M., Dubois, M. \& Valdois, S. (2013). The role of visual processing speed in reading speed development. Plos One, 8, 4, e58097.

Lobier, M., Peyrin, C., Pichat, C., LeBas, J.F. \& Valdois, S. (2012). Neural correlates of preorthographic character string processing. Neuropsychologia, 50, 9, 2195-2204.

Lobier, M., Peyrin, C., Pichat, C., Le Bas, J.F. \& Valdois, S. (2014). Visual processing of multiple elements in the dyslexic brain: Evidence for a superior parietal dysfunction. Frontiers in Human Neurosciences, 8, 479.

Lobier, M., Zoubrinetzky, R. \& Valdois, S. (2012). The visual attention span deficit in developmental dyslexia is visual and not verbal. Cortex, 48, 6, 768-773.

Marois, R., Chun, M.M. \& Gore, J.C. (2000). Neural correlates of the attentional blink, Neuron, 28, 299-308.

Martelli, M. Di Filippo, G., Spinelli, D. \& Zoccolotti, P. (2009). Crowding, reading and developmental dyslexia. Journal of Vision, 9, 4, 1-18.

Mazza, S. \& Naegele, B. (2004). Test d'attention soutenue : PASAT modifié, adaptation française, Collection : Tests et matériel en orthophonie, éd. Solal.

Merck, C., Charnallet, A. \& Auriacombe, S. (2011). La batterie d'évaluation des connaissances sémantiques du GRECO (BECS-GRECO): validation et données normatives. Revue de neuropsychologie, 3, 235-255.

Mort, D.J., Malhotra, P., Mannan, S.K., Rorden, C., Pambakian, A. et al. (2003). The anatomy of visual neglect. Brain, 126, 1986-1997.

Nobre, A.C., Sebestyen, G.N., Gitelman, D.R., Mesulam, M.M., Frackowiak, R .S. \& Frith, C.D. (1997). Functional localization of the system for visuospatial attention using positron emission tomography. Brain, 120, 515-533.

Peyrin, C., Démonet, J.F., Baciu, M., LeBas, J.F. \& Valdois, S. (2011). Superior parietal lobe dysfunction in a homogeneous group of dyslexic children with a single visual attention span disorder. Brain \& Language, 118, 128-138.

Peyrin, C., Lallier, M., Démonet, J.F., Pernet, C., Baciu, M., LeBas, J.F. \& Valdois, S. (2012). Neural dissociation of phonological and visual attention span disorders in 
developmental dyslexia: fMRI evidence from two case studies. Brain \& Language, 120 (3), 381-394.

Pisella, L., Biotti, D. \& Vighetto, A. (2015). Combination of attentional and spatial working memory deficits in Balint syndrome. Special issue on "Competitive visual processing across space and time: Interactions with memory", Annals of the New York Academy of Sciences, 1339, 165-175.

Pisella L., Blangero, A., Tilikete, C., Biotti, D., Rode, G., Vighetto, A., Mattingley, J.B. \& Rossetti, Y. (2013). Attentional disorders. In: K. Ochsner \& S. Kosslyn (Eds) : The Oxford Handbook of Cognitive Neuroscience, Volume 1 (pp. 319-350). Oxford University Press, Oxford, UK.

Pisella, L., Gréa, H., Tilikete, C., Vighetto, A., Desmurget, M., Rode, G., Boisson, D. \& Rossetti, Y. (2000). An 'automatic pilot' for the hand in human posterior parietal cortex: toward reinterpreting optic ataxia. Nature Neuroscience, 3, 7, 729-736.

Posner,M.I. (1980). Orienting of attention. Quarterly Journal of Experimental Psychology, 32, 3-25.

Reilhac, C., Peyrin, C., Démonet, J.F. \& Valdois. S. (2013). Role of the superior parietal lobules in letter-identity processing within strings: fMRI evidence from skilled and dyslexic readers. Neuropsychologia, 51, 4, 601-612.

Reilhac, C., Bosse, M.L. \& Valdois, S. (submitted). Phoneme awareness, visual attention span and rapid automatized naming disorders in poor readers: the prevalence issue.

Roach, N.W. \& Hogben, J.H. (2004). Attentional modulation of visual processing in adult dyslexia. Psychological Science, 15, 10, 650-654.

Roussel, M. \& Godefroy O. (2008). La batterie GREFEX : données normatives. GREFEX (éd.), Fonctions exécutives et pathologies neurologiques et psychiatriques , 231-266.

Ruffino, M., Gori, S., Boccardi, D., Molteni, M. \& Facoetti, A. (2014). Spatial and Temporal attention in developmental dyslexia. Frontiers in Human Neuroscience, 8, 331.

Ruffino, M., Trussardi, A. N., Gori, S., Finzi, A., Giovagnoli, S., Menghini, D. et al. (2010). Attentional engagement deficits in dyslexic children. Neuropsychologia, 48, 3793-3801.

Saksida, A., lannuzzi, S., Bogliotti, C., Chaix, Y., Démonet, J.F., Bricout, L. et al. (2016). Phonological skills, visual attention span and visual stress in developmental dyslexia. Developmental Psychology, 52, 10, 1503-1516.

Schenkenberg, T., Bradford, D.C. \& Ajax, E.T. (1980). Line bisection and unilateral visual neglect in patients with neurologic impairment. Neurology , 30 (5), 509-509.

Shomstein, S., Lee, J. \& Behrmann, M. (2010). Top-down and bottom-up attentional guidance: investigating the role of the dorsal and ventral parietal cortices. Experimental Brain Research, 206, 197-208. 
Sireteanu, R., Goertz, R., Bachert, I. \& Wandert, T. (2005). Children with developmental dyslexia show a left visual «minineglect ». Vision Research, 45, 3075-3082.

Shomstein, S., Lee, J., \& Behrmann, M. (2010). Top-down and bottom-up attentional guidance : investigating the role of the dorsal and ventral parietal cortices. Experimental Brain Research, 2006, 2, 197-208.

Striemer C., Blangero A., Rossetti Y., Boisson D., Rode G., Vighetto A., Pisella L. \& Danckert J. (2007) Deficits in peripheral visual attention in patients with optic ataxia. Neuroreport, 18, 11, 1171-1175.

Vallar, G. \& Perani, D. (1987). The anatomy of spatial neglect in humans. In: Jeannerod, M. (Ed.), Neurophysiological and Neuropsychological Aspects of Spatial Neglect (pp. 235258). North-Holland: Elsevier Science Publishers.

Valdois, S., Bidet-Ildei, C., Lassus-Sangosse, D., Reilhac, C., N'Guyen, M.A., Guinet E. \& Orliaguet, J.P. (2011). A visual processing but no phonological disorder in a child with mixed dyslexia. Cortex, 47, 1197-1218.

Valdois, S., Guinet, E. \& Embs, J.L. (2017). Evadys : Outil diagnostic des troubles de l'empan visuo-attentionnel. Lyon : Happy Neuron (www.happyneuronpro.com).

Valdois, S., Lassus-Sangosse, D. \& Lobier, M. (2012). Impaired letter string processing in developmental dyslexia : what visual-to-phonological code mapping disorder ? Dyslexia, 18 (2), $77-93$

Valdois, S., Peyrin, C., Lassus-Sangosse, D., Lallier, M., Démonet, J.F. \& Kandel, S. (2014). Dyslexia in a French Spanish bilingual child: Behavioural and neural modulation following a specific VA span intervention program. Cortex, 53, 120-145.

Valdois, S., Roulin, J.L. \& Bosse, M.L. (Submitted). Reading fluency depends on prereaders' ability to process multiple visual elements in parallel.

Van den Boer, M., de Jong, P.F. \& Haentjens-van Meeteren, M.M. (2013). Modeling the length effect : Specifying the relation with visual and phonological correlates of reading. Scientific Studies of Reading, 17, 4, 243-256.

Vidyasagar, T. R. \& Pammer, K. (2010). Dyslexia: a deficit in visuo-spatial attention, not in phonological processing. Trends in Cognitive Science, 14, 57-63.

Visser, T. A., Boden, C. \& Giaschi, D. E. (2004). Children with dyslexia: evidence for visual attention deficits in perception of rapid sequences of objects. Vision Research, 44, 21, 2521-2535,

Warrington, E.K. \& James, M. (1991). The Visual Object and Space Perception Battery. Bury St Edmunds Thanes Valley Test Company.

Whitney, D. \& Levy, D.M. (2010). Visual crowding: a fundamental limit on conscious perception and object recognition. Trends in Cognitive Sciences. 15, 4, 160-168.

Wojciulik, E. \& Kanwisher, N. (1999). The generality of parietal involvement in visual attention. Neuron, 23, 4, 747-764. 
1

\section{列}

14

Yantis, S., Schwarzbach, J., Serences, J.T., Carlson, R.L., Steinmetz, M.A., Pekar, J.J. et al. (2002). Transient neural activity in human parietal cortex during spatial attention shifts. Nature Neuroscience, 5, 10, 995-1002.

Zoubrinetzky, R., Bielle, F. \& Valdois, S. (2014). New insights on developmental dyslexia subtypes: Heterogeneity of mixed reading profiles. Plos One, 9(6): e99337.

Zoubrinetzky, R., Collet, G., Serniclaes, W., N'Guyen-Morel, M.A. \& Valdois, S. (2016). Relationships between categorical perception of phonemes, phonological awareness, and visual attention span in developmental dyslexia. Plos One, 11(3): e0151015 